\title{
Ranking EU Agricultural Sectors under the Prism of Alternative Widths on Window DEA
}

\author{
Leonidas Sotirios Kyrgiakos ${ }^{1, *} \mathbb{1}$, George Vlontzos ${ }^{1}$, and Panos M. Pardalos ${ }^{2}$ \\ 1 Department of Agsriculture Crop Production and Rural Environment, University of Thessaly, Fytoko, \\ 38446 Volos, Greece; gvlontzos@agr.uth.gr \\ 2 Department of Industrial and Systems Engineering, University of Florida, 401 Weil Hall, \\ Gainesville, FL 32611-6595, USA; pardalos@ise.ufl.edu \\ * Correspondence: lkyrgiakos@uth.gr; Tel.: +30-242-109-3013
}

check for updates

Citation: Kyrgiakos, L.S.; Vlontzos, G.; Pardalos, P.M. Ranking EU Agricultural Sectors under the Prism of Alternative Widths on Window DEA. Energies 2021, 14, 1021. https://doi.org/10.3390/en14041021

Academic Editor: Mariusz

Jerzy Stolarski

Received: 3 January 2021

Accepted: 11 February 2021

Published: 16 February 2021

Publisher's Note: MDPI stays neutral with regard to jurisdictional claims in published maps and institutional affiliations.

Copyright: (c) 2021 by the authors. Licensee MDPI, Basel, Switzerland. This article is an open access article distributed under the terms and conditions of the Creative Commons Attribution (CC BY) license (https:// creativecommons.org/licenses/by/ $4.0 /)$.

\begin{abstract}
Providing food security while preserving natural resources and reducing the use of production factors (land, labor, and capital), is a critical challenge for EU agricultural sectors in the 21st century. Sustainable Development goals adoption has increased the need for eliminating Greenhouse gas emissions across all EU sectors, while production should remain stable or even increase. For this purpose, Window Data Envelopment Analysis (DEA) has been selected as a benchmarking technique, in order to assess input use efficiency of agricultural sectors of EU countries for the 20052019 period. Moreover, three-year projections (until 2022) have been calculated in order to acquire future efficiency scores. Emphasis has been given on the selection of alternative window widths, examining their influence on calculating efficiency scores for both projected and actual dataset. From a methodological point of view, this paper aims to highlight the assumption of zero technological change within Window DEA frames and present their differences. At the same time, results indicate that Estonia (1.000), the Netherlands (0.999) and Slovenia (0.999) are the most efficient countries in terms of input use efficiency, while Finland, UK, and Hungary $(0.670,0.755$ and 0.771$)$ score the least. Countries of central Europe (Hungary, Czech Rep., Croatia, Slovakia, and Austria) should redesign their agricultural strategies, so as to achieve the nine objectives of the upcoming CAP (2021-2027).
\end{abstract}

Keywords: Window DEA; window width; efficiency; projection; input optimization; crop production

\section{Introduction}

Existence and evolution of humanity is strongly linked with development of agriculture. It was no later than the end of World War II when the EU decided to support the primary sectors of member states by establishing the first mutually agreed policy tool, the Common Agricultural Policy (CAP). Price support and export refund systems had a significant negative impact on global agricultural trade, suppressing at the same time natural resources and the environment in rural areas [1]. CAP strategic goals have been customized periodically since then, so as to meet global food security and safety standards, promoting at the same time fairer trade, and increased competiveness. European Commission (EC) has set nine key objectives through the upcoming CAP (2021-2027) period, which can be grouped in three basic categories: (1) economy (2) environmental protection and (3) rural communities support, in order to promote sustainable development and achieve Sustainable Development Goals (SDGs) until 2030 [2].

The assessment of policy interventions on both operational and environmental level is very crucial. The policy framework developed under the Agenda 2000 reform is more market oriented, introducing schemes such as decoupled payments, requiring robust approaches for evaluating their suitability, applicability, and effectiveness [3]. This study introduces such an assessment tool, taking into consideration both the diversified structural characteristics of EU member states primary sectors and the influence of the market on them. Data Envelopment Analysis (DEA) is used for assessing efficiency of multiple 
Decision Making Units (DMUs) in various sectors. DEA can be a useful tool, indicating the inputs or outputs that are not used efficiently, leading to the point solutions for the optimization of a given system. The wide applicability of DEA is based on the fact that efficiency scores are calculated based on the existing DMUs without the need for predefined optimum values. For this reason, DEA has been used for the improvement of various sectors such as banking systems [4], healthcare systems [5], tourism [6], logistics [7] and agriculture both in crop and livestock production [8,9].

\section{Literature Review}

On the line of SDGs, EU agriculture should succeed on assuring food security and environmental protection, while on the same time on securing fair income for farmers.

\subsection{Land}

In the case of agricultural sector efficiency assessment, DEA methodology has been used in order to evaluate total factor productivity (TFP) [10], revealing the need for improvement between countries with similar structural profiles. Under the scope of energy usage and natural environment protection, Zhou et al. have assessed changes of environmental efficiency between years 2006-2015, revealing geographical patterns that should be further supported from the government, connecting efficiency scores with regional characteristics [11]. Feasible solutions for crop management can be provided through DEA results, has led to improved management of available agricultural land, as a whole, in the most efficient way, combining crops' productive needs with regional structural characteristics [12]. On the same approach, Toma et al. [13] have classified 36 countries according to their geographical characteristics, clustering them in three distinct groups (plain, hill, mountainous), using as inputs the three production factors (land, labor and level of mechanization) and production value as the output. Efficient land use can be achieved by examining Greenhouse Gas (GHG) emissions of different crop types, leading to agriculture with lower emissions [14] As Bournaris et al. suggest, DEA can provide meaningful results about crop selection in greenhouse farming, optimizing the use of all inputs involved [15].

\subsection{Energy}

As FAO suggests, agriculture consumes $30 \%$ of total energy spent, while the greatest share of this energy is referring to in-farm procedures [16]. On a global scale, constant population growth and increased food demand had led to intensification of production. Despite the urge for covering the previous mentioned needs, agricultural land has remained in similar levels from 1961 to 2014, resulting in higher energy inputs, agrochemicals, and fertilizers, per land unit. It should be mentioned that Pellegrini et al. confirm the existence of Jevons paradox in agriculture, claiming that technology evolution was not accompanied by input minimization, due to the extended use of these innovations for achieving higher yields. [17].

Energy consumption affects famers' income, having frequently a negative impact on natural resources. That is the reason conventional agriculture systems are gradually transforming to sustainable ones, using minimum energy resources and producing a fair output as yield [18]. Literature review of Smith et al. indicates higher energy efficiency scores for organic agriculture, but mainly in the crop production domain, while conventional livestock farms achieve higher efficiency scores than the organic ones [19]. According to FADN database, Guth and Smedzik-Ambrozy analyzed EU agricultural sectors, concluding that countries with the highest amounts of labor, land and capital achieve the higher efficiency scores, underlying the need for restricting measures in order to promote environmental and societal development [20]. DEA results can contribute to sustainable intensification ameliorating in-farm operations (energy consumption, integrated pest management, greener logistics) and policies promoting environmental protection on a national and EU level [21]. 
Another advantage of DEA methodology, apart from calculating efficiency scores of all DMUs of a given system and ranking them from the most to the least efficient, is slacks calculation. Slacks are used to quantify the changes that should occur in each variable, in order for a DMU to be efficient. Their interpretation is meaningful both for stakeholders and policy makers in order to take final decisions, while from analyst's perspective, it can be signified which slacks have major or minor importance. Assessment of French diary sector according to their energy use, has resulted in a positive relation between subsidies and energy use slacks, meaning that larger farms have higher amounts of exploited energy, than the smaller ones proportionally [22]. This is an applicable example of slacks contribution in energy use minimization on the farm level, but also indicates potential policy reformation for French livestock sector. Adjustment of slacks has resulted in improved efficiency scores, providing optimal solutions for both developed and developing countries, regarding their energy consumption and $\mathrm{CO}_{2}$ emissions [23]. Slack-Based-Model (SBM) implementation from Apergis et al. raises concern about the decreasing energy efficiency of OECD countries, proving the feasibility of methodology in real case problem solving [24].

\subsection{GHG Emissions}

DEA methodology has also been used to assess the energy efficiency of national agricultural sectors, in relation to GHG emissions as an undesirable output. According to the Window DEA methodology of Pishgar-Komleh et al., Spain, Greece, Italy and Malta achieved the highest efficiency scores, presenting outcomes both using or neglecting $\mathrm{CO}_{2} \mathrm{eq}$ as an output [25]. Similar results have been obtained using DEA for 2005 and 2010 for agricultural sectors of European countries with the use of Gross Value Added (GVA) from agriculture to GHG (GVA/GHG) as an eco-efficiency index [26]. High improvement potential of up to $56 \%$ has been identified applying DEA for the reduction of $\mathrm{CO}_{2}$ emissions in Chinese provinces [27]. The authors underline the need for incentives from government's side to farmers, for higher rates of technology acceptance that will reduce GHG emissions and align Chinese agricultural undesirable output with global standards. Moreover, DEA results have revealed $70 \%$ space for improvement in energy saving for the Spanish supply chain of agricultural products [28]. Focusing on agricultural inputs and especially fertilizers, slight improvements have been observed in Latvian agricultural sector, providing at the same time the appropriate methodology for continuous monitoring [29]. On a farm level, DEA can also be applicable, while an overall reduction in carbon footprint could be achieved with the implementation of proposed actions, leading to a cleaner production [30].

Literature review of Mardani et al., reveals the extensive applicability of DEA methodology for optimization of energy consumption and environmental protection under operational terms [31]. DEA results can provide meaningful insights for efficiency assessment of multi-sectorial industries while providing feasible solutions for energy optimization, accentuating the importance for green technology alternatives [32]. Another remark from the previous survey, is the calculation of efficiency scores depending on the given objective every time, proposing methodology for managerial or environmental-based results. New approaches provide the appropriate tools for mathematical expression of limiting factors that cannot be controlled both for inputs or outputs (e.g., reduced efficiency of solar panels due to environmental conditions), depicting reality more sufficiently [33]. Combining the above-mentioned surveys, Mo and Wang have estimated environmental sustainability of road transport for OECD countries, an approach that can be applied in the agricultural logistics or in the whole agricultural supply chain as a whole [34].

Focusing on agriculture, the number of publications per year presenting combination of DEA + Life Cycle assessment (LCA) have been increased during the 2003-2018 time period, due to the increased interest for cleaner production systems and eco-friendly products [35]. Farm specialization is very crucial, in order to achieve improved management status and efficient resources handling. Examining all inputs involved in winter wheat production in Poland, researchers realized excessive use of fertilizers, seeds and fuel, providing to local farmers additional information for inputs minimization [36]. Another 
survey, highlights the resource saving on energy and water by decreasing cotton seed on optimum levels [37]. It should be underlined that no statistical differences have been pointed out between large and small scale farms, regarding eco-efficiency.

Introduction of uncertainty to DEA approach for measuring eco-efficiency can alter the final outcome, thus it is essential to be taken into consideration especially in systems that are affected from various factors [38]. Statistical significance can be assessed for multiple DMUs over frames of a certain period of time, checking results validity [39]. Defining weights in DEA model is another approach of assuring results implementation in real case scenarios, especially when dealing with small samples [40]. Even though there are several studies examining environmental and economic aspects of agricultural production, only few of them are connecting their results with society, due to lack of the appropriate data or methodology [41].

\subsection{Labor}

Labor, expressed as Annual Working Units (AWU), is one of the three main production factors in agriculture [42]. Differences in labor productivity have been observed among EU countries, something which expected to be, because of differences of the structural characteristics of their holdings and value chains [43]. Additionally, soil erosion, local economic prosperity and population density seem to be the most crucial factors affecting labor productivity. Results are correlated with educational level of farmers highlighting the need for training, which will lead to a better communication between producers and agricultural consultants. It should be mentioned though, that the EU is in a transitional period of full digitalization. Automation and robotics will totally reform agriculture globally, creating opportunities and negative externalities for labor [44].

\subsection{Policy}

Policy assessment can rely on DEA results. Rybaczewska-Błazejowska and Gierulski have concluded to two large groups (efficient (10) and inefficient (18)) of EU-28 countries according to their eco-efficiency status, examining both for environmental and operational performance [45]. Greatest factor that limits eco-friendliness in EU agriculture is the excessive use of fuels and fertilizers, contributing to larger releases of GHG emissions. A controversial issue that has emerged with overpopulation is the land use for food or fuel. DEA methodology can be used in order to assess the crops with high input-efficiencies in certain regions and provide the appropriate answers, given the fact that there is a clear managerial strategy [46]. Depending on the approach needed in the policy creation procedure, Vázquez-Rowe and Iribarren have proposed a five stage Boolean tree of DEA + LCA approach, so as to facilitate the above-mentioned procedure [47]. Risk management can also be minimized by the usage of DEA. Proposed methodology analyzes all different risks as inputs while all innovations are considered to be outputs [48].

DEA has been used in combination with Artificial Neural Networks (ANNs) giving meaningful results for national agricultural sectors' performance [49]. The greatest advantage of the previous application is the creation of emissions forecast, a handful tool for policy makers and stakeholders involved, for making valid decisions in advance and achieve zero emissions goals by 2030. Another survey assesses the applicability of DEA + ANNs of ranking "green suppliers" providing future perspectives [50]. Overall, forecasts provide the opportunity to quantify future situations with high accuracy, facilitating the creation of multiple scenarios for easier risk management. Sueyoshi and Gotohave proposed a methodology on handling imprecise data when performing DEA for computing projected efficiency scores, calculating upper and lower hyperplanes for values replacement when needed [51]. In this survey, an alternative methodology of future projections regarding benchmarking and efficiency scores is introduced, combining DEA with time series forecast focusing on assessing input use efficiency of the EU agricultural sector, providing valid future results. 


\section{State of the Art}

Mardani et al. mentioned in their extended literature review about different types of DEA models that only 5 out of 163 papers referred to the implications of the Window DEA model [31], proving the need for further deepening on the specific methodology. This approach provides the ability for efficiency assessment of multiple years and DMUs, being the reason it should be further assessed. Evolution of technology has permitted the construction and manipulation of large datasets, while future projections with high accuracy can be obtained, enhancing the applicability of Window DEA. Estimating efficiency scores for the period of 2012-2018 for Iranian ports, Zarbi et al. (2019) chose arbitrary window width equal to 4 [52]. Changing window width would not lead to radical changes, because of the relative short period of time analyzed. Another study that has implemented Window DEA methodology for energy efficiency in the Spanish electricity sector, used an arbitrary window width of five years for an overall 9-year-period (2006-2015) [53]. A similar approach with this paper has been followed for the assessment of dairy farming system in Iran, exploring differences between different window widths when using Window DEA [54]. Differences indicate a decreasing average score for all DMUs involved, due to the enlargement of window width. Thus, it should be underlined that the ideal window length has not been estimated, so that the ranking differences can become apparent between the ideal and other window widths. Window DEA regarding energy use and social characteristics has been perform for Chinese provinces, revealing efficiency gaps between them [55]. In that survey, a 2-year-window length has been selected for the energy use assessment for the years 2005-2014. Taking into consideration all the above-mentioned papers and given the fact that window DEA is not widely explored, assessment of window width influence has been made in an extended period of time (with actual and projected dataset), so as to indicate the resulting differences.

\section{Structure and Scope}

This paper consists of the following sections. The Introduction and Literature review highlight the contribution of DEA methodology regarding efficiency of production factors in agriculture and environmental performance, as well as its use in combination with other well stated methodologies such as LCA and ANNs. The State of the Art section signifies the impact of this paper, in comparison with other similar articles. The Methodology section presents briefly the DEA Analysis and focuses on Window DEA Analysis methodology and selection of appropriate window width. Moreover, the Data section provides a detailed description about data source, type of variables and overall data handling. In the Results section, descriptive statistics of the sample provide a clear image to the reader for all inputs and outputs involved. Moreover, estimations of ideal window width and final rankings for actual (2005-2019) and projected (2005-2022) data set are presented, emphasizing on differences between different window widths. The Discussion section addresses the main findings in an applicable way for EU-members, compares findings with related surveys, and connects findings with specific SDGs. Main findings referring to the methodological approach and possible implementation of actual results are included in the Conclusion section. Last but not least, this section includes limitations of this study and potential future contribution in the field.

The scope of this study is to introduce a methodological approach for assessing the efficiency of the primary sectors of EU member states after the implementation, on an operational level, of the AGENDA 2000 CAP. This is quite important due to the radical characteristics of this reform, which is the reduction of intervention on the decision making process of agricultural holdings, and the increase of market forces influence on the value chains of agricultural products. The chosen methodological approach allows us to present a prognosis of efficiency performance of member states, following similar approaches of other economic sectors, where institutional intervention is either minimized or absent. The examination of the reliability of alternative widths of Window DEA model, improves the suitability of this model for this assessment. The contribution of this paper to academic 
literature is to highlight differences in final rankings between ideal and arbitrary chosen window widths, due to the existence of zero technological change assumption within window when performing Window DEA, as it is described in the Methodology section.

\section{Methodology}

\subsection{DEA Analysis}

DEA focuses on measuring productivity of the same and comparable values or groups that can be defined as decision making units (DMUs). The first attempt to evaluate the efficiency of DMUs was made by Farrell in 1957 [56]. Based on his work, Charnes, Cooper, and Rhodes introduce a newer evaluation method for different DMUs with multiple inputs and outputs [57]. More specifically, DEA is a non-parametric method, which uses linear programming techniques to evaluate the effectiveness of DMUs. Efficiency is defined as the ratio of inputs to outputs. Efficiency has been calculated according to the following formula [58]:

$$
\begin{gathered}
\varphi^{*}=\min \varphi \\
\text { s.t } \sum_{j=1}^{n} x_{i j} \lambda_{j} \leq x_{i} \quad i=1,2, \ldots, m \\
\sum_{j=1}^{n} y_{r j} \lambda_{j} \geq \varphi y_{r} \quad r=1,2, \ldots, m \\
\lambda_{j} \geq 0 \quad j=1,2, \ldots, n
\end{gathered}
$$

where $\varphi^{*}$ represents the relative technical efficiency of $x_{i j}$ and $\lambda_{j}$ the weights in order to define the set of DMUs where $\varphi^{*}=1$ and calculate the efficiency scores for the rest DMUs afterwards $\left(\varphi^{*}<1\right)$. It should be noted that DEA can increase efficiency of DMUs either by minimizing inputs (input-oriented) or maximizing outputs (output-oriented) given the same amount of all factors involved. Input-oriented DEA is preferable in most cases in agriculture, due to the fact that limited exploitation of natural resources and reduced cash flows for inputs from farmers' side are preferred [35]. That is the reason input-oriented approach has been selected for this analysis.

Furthermore, as seen in the literature review, undesirable factors can be handled with DEA. You and Yan present four ways of treating undesirable factors: (1) complete ignorance, (2) consider undesirable outputs as inputs, (3) non-linear monotonic decreasing approach, (4) linear monotonic decreasing approach [59]. For the purpose of this survey option 3 has been selected in order to handle the amounts of emitted emissions by transposing the $\mathrm{CO}_{2}$ amount. The same methodology was proposed by Scheel (2001) when dealing with both desirable and undesirable factors in DEA model [60]. Data normalization can also be used to deal with undesirable factors, thus it should be noted that some of the available information is lost in the process of data manipulation, as well as results interpretation, to people who are not familiar with the above methodology [61].

\subsection{Window DEA Analysis}

Although the aforementioned approach of DEA can be used in order to assess the efficiency of different DMUs in a given period of time, thus a new approach was needed for time series due to the fact that every unit is considered to be independent even if it is the same DMU in another period of time. For this purpose, a window DEA has been proposed, based on the principles of moving average [62]. Applying Window DEA, a reference period should be defined and then data are grouped in distinct groups (windows). This framework permits the comparison of different DMUs within the given window and an overall average score can be retrieved in the end of this procedure as the mean of all years involved. It should be clarified that efficiency scores for a given period and same DMU are different, due to the fact that it is compared with a different dataset.

Window DEA implementation is summarized in Table 1. Subsets of initial dataset are constructed in accordance with the chosen window length. Average scores per Year and per Country $(A S Y C)$ are obtained in order to calculate mean efficiency scores for every country in the predefined period of time. 
Table 1. Window DEA analysis.

\begin{tabular}{|c|c|c|c|c|c|c|c|c|c|c|c|c|c|}
\hline Country (x) & $\mathbf{t}$ & $t+1$ & $t+2$ & $t+3$ & $t+4$ & $t+5$ & $\ldots$ & $t+k-5$ & $t+k-4$ & $t+k-3$ & $t+k-2$ & $t+k-1$ & $t+k$ \\
\hline $\begin{array}{l}\text { Window } 1 \\
\text { Window } 2 \\
\text { Window } 3\end{array}$ & & & & & - & & & & & & & & \\
\hline $\begin{array}{c}\vdots \\
\text { Window } \mathrm{n}-2 \\
\text { Window } \mathrm{n}-1 \\
\text { Window } \mathrm{n} \\
\end{array}$ & & & & : & : & : & $\vdots$ & & & & & & \\
\hline$A S Y C^{*}$ & (1) & (2) & (3) & (4) & (5) & (6) & $(\ldots)$ & $(n-2)$ & $(n-1)$ & (n) & $(\mathrm{n}+1)$ & $(\mathrm{n}+2)$ & $(n+3)$ \\
\hline
\end{tabular}

${ }^{*} A S Y C=$ Average Efficiency Score/Year/Country.

\subsection{Window Width}

The selection of the DEA window width is very crucial for the result extraction. As Asmild et al. stated, window width should be short enough so as to permit the comparison between different windows and contain enough elements for accurate efficiency measurement [63]. Although width in many papers selection is arbitrary, it is essential to use the appropriate methodology $[64,65]$. For this purpose, the ideal window width has been calculated, performing DEA model for each year $(i)$ for the reference period (1-T) and by window $(j)$, acquiring the mean of every year $\left(M_{i j}\right)$ for any given $j$. The construction of a new matrix $(A)$ is following, calculating Equation (2), where Mean ${ }^{i}$ is the average value of year $(i)$ for every $j$.

$$
v_{i j}=\frac{M_{i j}-\text { Mean }^{i}}{M_{e a n}} * 100 \%
$$

For every year in matrix $A, A b s \sin _{i j}=\left|\min \left(v_{i j}\right)\right|$ are selected. The window width which acquires the greater number of $A b s m_{i j}$ is the appropriate one. Thus, it should be underlined that window DEA imposes an assumption of zero technological change within the window and this should be taken into consideration when performing Window DEA Analysis [63].

\subsection{Data}

For data selection, variables that compose production factors in agriculture (land, labor, and capital) were selected for efficiency estimation of EU countries (Table 2). Selected variables are Total Used Agriculture Area $(U A A)$, Labor force $(L)$ and Fixed Capital Consumption (FCC) which express the previous mentioned aspects. Data for standard inputs such as Seeds and Planting Stock (SPS), Plant Protection Products (PPP), and N, $P$ fertilization (NFert, PFert) were taken into consideration due to the high amounts of energy consumed for their production, especially for fertilizers. Moreover, Energy (EN) has also been included as a separate variable due to the need for emphasizing in energy consumption minimization, following the EU guidelines for the benchmarking process. As outputs, monetary values of Total agriculture output (TO) and $\mathrm{CO}_{2 \mathrm{eq}}$ emissions (EM) have been taken into consideration. All data have been acquired through EUROSTAT database and more precisely: [aact_eaa07], [nrg_bal_s], [aei_fm_usefert], [env_air_gge], [apro_cpshr] [66].

The data set selected refers to the time period after the implementation of AGENDA 2000 in operational terms. Cyprus, Malta, and Luxembourg were excluded due to their relatively small agricultural sector size, when compared with the other EU countries. On the other hand, data from the Norwegian agricultural sector was added, due to the strong trade relationship of the country with the EU and the fact that its agricultural sector presents similar characteristics with the rest of the Scandinavian countries. Considering that all available data were referring to 2005 until 2019, 3-year data projection has been made with a view to provide an up to date information, extending the reference period until 2022. It should be underlined that EUROSTAT had already made estimations for 2020 for some of the above-mentioned data. To avoid the confusion of projection data methodologies, 2019 
has been set as the ending year of the dataset and forecasts have been equally generated. Data projections have been obtained using Double Exponential Smoothing for Time Series in Minitab 17 Statistical Software [67]. DEA and window DEA results have been acquired using Benchmarking library in R Studio [68].

Table 2. Data selection Inputs and Outputs for reference period 2005-2019.

\begin{tabular}{|c|c|}
\hline \multicolumn{2}{|c|}{ Reference Period: 2005-2019 } \\
\hline Variable & Measurement Units \\
\hline \multicolumn{2}{|c|}{ Inputs } \\
\hline Total Used Agriculture Area $(U A A)$ & 1000 Hectare (ha) \\
\hline Labor $(L)$ & 1000 Annual Working Units (AWU) \\
\hline Fixed Capital Consumption (FCC) & Million Euro $(€)$ \\
\hline Energy $(E N)$ & Thousand Tonnes of oil equivalent (TOE) \\
\hline Seeds and Planting Stock (SPS) & Million Euro $(€)$ \\
\hline Plant Protection Products $(P P P)$ & Million Euro $(€)$ \\
\hline Consumption of N-Fertilizers (NFert) & Tonnes \\
\hline Consumption of P Fertilizers (PFert) & Tonnes \\
\hline \multicolumn{2}{|c|}{ Outputs } \\
\hline Crop output $(T O)$ & $\begin{array}{l}\text { Production value at basic price, Million Euro } \\
\qquad(€)\end{array}$ \\
\hline Emissions $(E M)$ & Th. Tonnes of Greenhouse gases $\left(\mathrm{CO}_{2 \mathrm{eq}}\right)$ \\
\hline
\end{tabular}

Providing a better understanding of all procedures involved, a panel of 26 EU countries, 10 different variables and a time period of 18 consecutive years has been constructed, using EUROSTAT's data. Figure 1 demonstrates all steps followed until the extraction of final efficiency scores and rankings per country. Further explaining the above-mentioned methodology and taking as an example the whole panel (actual and projected data), a subset of initial dataset has been constructed for each reference period of window width (9). The next step includes DEA implementation for each subset so as to acquire efficiency scores for every window. As mentioned in the Methodology section, different efficiency scores are obtained for the same country and year between windows. For instance, efficiency scores for Austria 2015 differ in Window 1 and Window 2, due to the fact that it is compared with a new dataset. Following steps include the construction of a new data frame, in which all efficiency scores per window frame are collected and average scores per year and per country are calculated. Computation of mean efficiency scores is the last step, providing at the same time the corresponding rankings for every country after sorting the data.

A summarized viewpoint of Window DEA analysis is presented in Table 3. Diamondshaped data structures are built so as to provide average scores per year for every country. Mean of $A S Y C$ is the final score for each country but it should be stated that assessment of final rankings is more valuable than changes in the actual values of efficiency scores. 


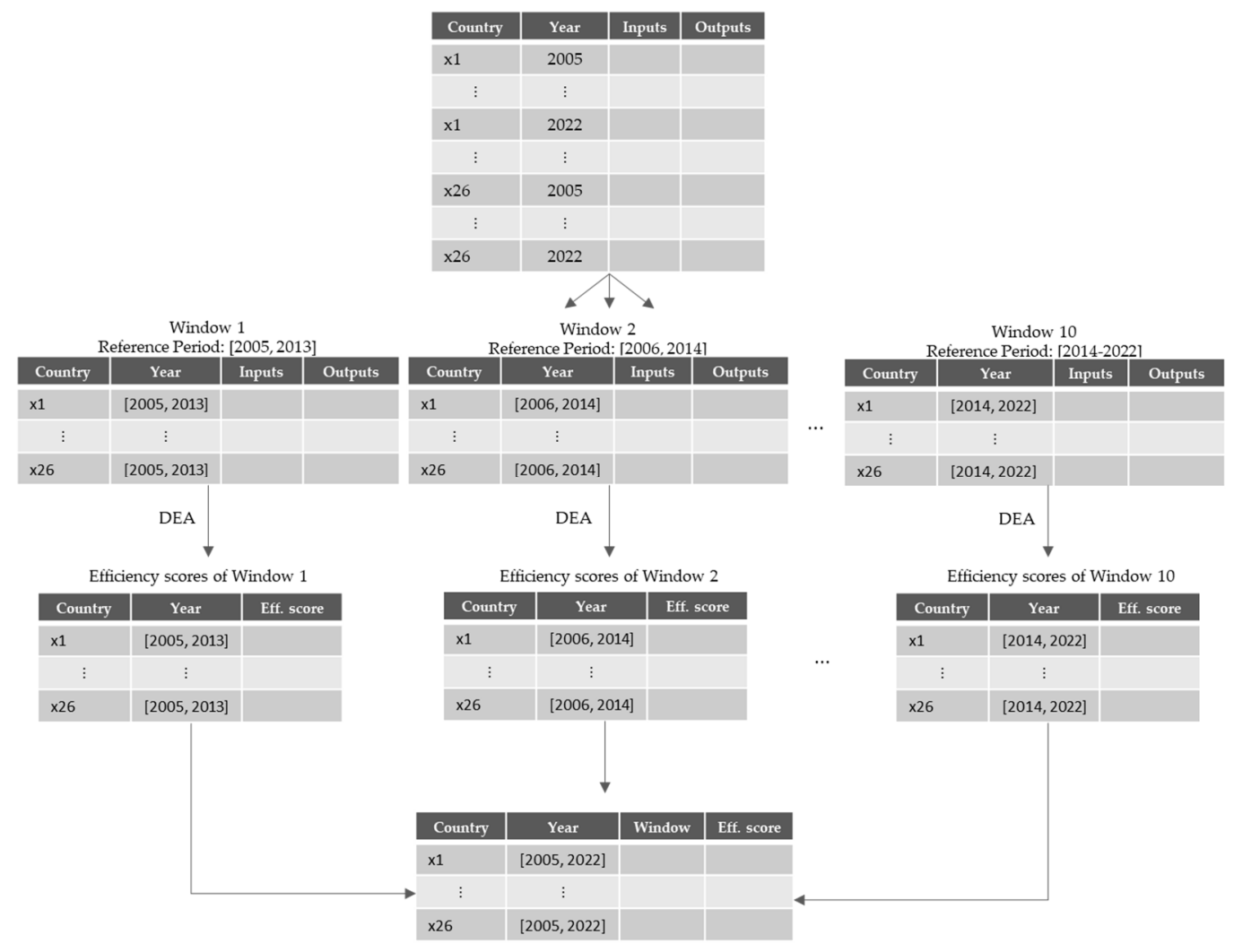

Figure 1. Step by step representation of the applied methodology.

Table 3. Window DEA analysis representation for actual and projected dataset.

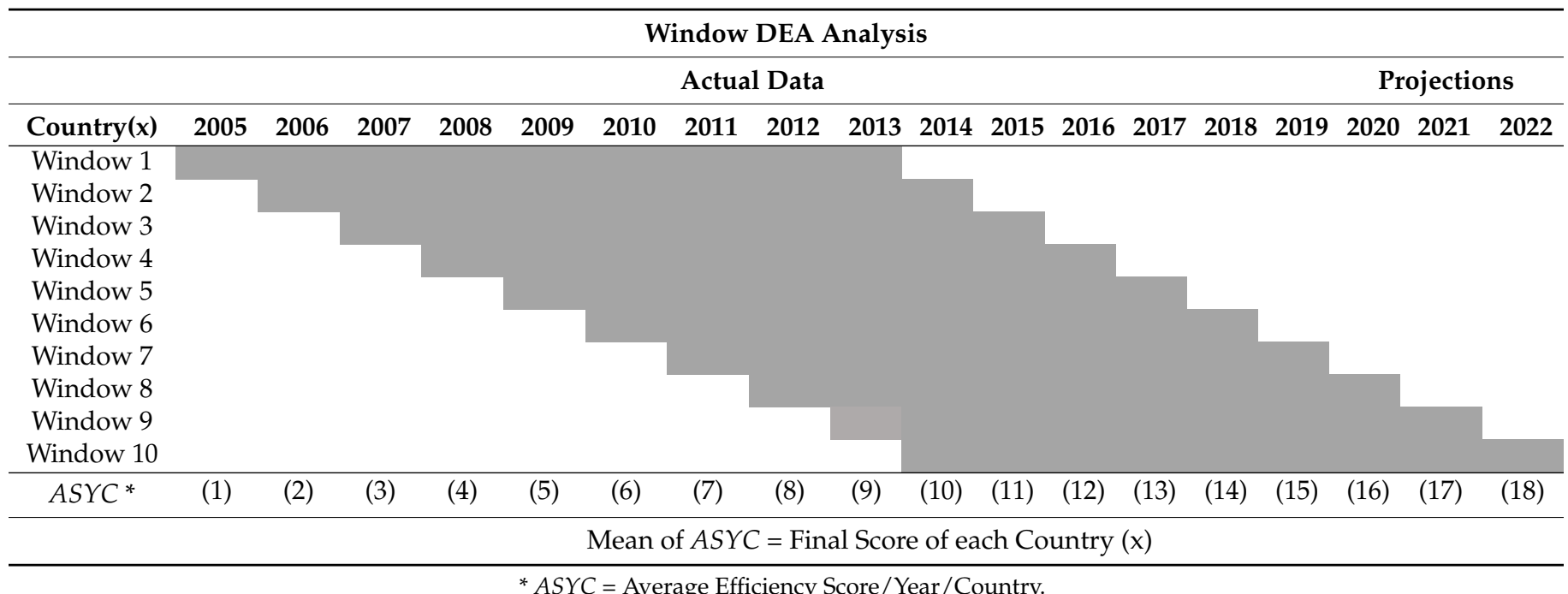

\section{Results}

\subsection{Descriptive Statistics}

Descriptive statistics of both inputs and outputs were examined before proceeding to the main analysis (Table A1 Appendix A). According to the UAA for the period 20052019, the greatest negative differences have been identified for Austria, Italy, and Poland $(-18.7 \%,-10.6 \%,-9.7 \%)$ while the agricultural area increased in the following countries: Latvia, Croatia, and Greece (13.0\%, $24.2 \%$, and $26.6 \%$ ). A slight decrease of $3.2 \%$ of $U A A$ was calculated for all countries involved. An overall drop of $29.0 \%$ for Labor force is being depicted, with Ireland being the only country presenting an $8 \%$ increase. On the other 
hand, the great decreases are highlighted for Estonia $(-50.1 \%)$, Slovakia $(-55.0 \%)$, and Bulgaria (-69.6\%). It should be underlined that even if Labor has been decreased, annual wage per AWU increased by approximately 20\% (base year $=2010$ ) [69].

Capital consumption from national agricultural sectors increased by $8.8 \%$, meaning that the EU agricultural sector is becoming more challenging, demanding higher financial resources from all stakeholders involved. European Commission report signifies that intermediate costs will keep increasing until 2030, leading to a more capital intensive agricultural domain [70]. The energy sector presents great differences between countries analyzed. Greece, Bulgaria and Ireland are the three countries achieved highest rates of energy minimization, thus Latvia, Romania, and Germany presented increases of more than $60 \%$. Considering Plant Protection Products, a total increase of $17.0 \%$ is being depicted, despite the EU's intense effort for agricultural chemicals reduction. The Netherlands has achieved an overall reduction of $(-20.4 \%)$ and $(-77.4 \%)$ in NFert, PFert fertilizers accordingly, which is the best performance from all countries involved. Crop output has increased by $10.2 \%$ for the period 2005-2019, with Latvia, Estonia, and Lithuania presenting the highest rates of improvement, while Italy, Germany and Finland have reduced rates $(-12.6 \%,-10.4 \%,-4.7 \%)$. Analysis of $\mathrm{eqCO}_{2}$ indicates that there is only a slight decrease of $-1.6 \%$ for the last 15 years, a not so overwhelming result, given the fact of technological progress and global pressures for zero emissions.

Figures 2 and 3 illustrate the above-mentioned results, which have been obtained during the initial stages of the analysis and provide a general picture of agricultural sectors of EU countries. In Figure 2, the Netherlands is an exceptional remark with very high needs in EN and SPS but very low needs in $L$ and $U A A$ achieving the fifth highest agricultural output. This can be easily explained, based on the great number of greenhouses which can be described as intense input, especially in energy demands for heating. Another remark that should be highlighted is referring to the cases of Estonia and Slovenia. Both of them have the least inputs and least outputs of all EU agricultural sectors but they present great differences in terms of inputs use efficiency as it will be presented in the Window DEA results section. It should be underlined that the two countries have significant differences in their climate, which has an immediate effect on the overall production.

Total UAA and EN were plotted together so as to examine Pellegrini's et al. statement about energy use in the EU agriculture [17] (Figure 4). Despite the fact that total UAA decreased by $3 \%$ from 2005 to 2019 , EN seems to have a significant increase of $16.9 \%$ from 2015 to 2019 . This can be partially explained from the recovery of EU countries after a long period of economic recession in EU countries. Moreover, it should be mentioned that the share of renewable energies in agriculture has remained on the same levels for the last two decades, signifying the need for finding more sustainable solutions for agricultural energy consumption.

In Figure 5, it is pointed out that there is not a great variance among examined countries apart from Germany and Greece regarding Annual Energy consumption. Despite the fact that Germany has a large variance through the reference period of this paper, other countries such as France, Portugal and the Netherlands appear with higher energy demands. That is the reason the two outliers identified in Germany were accepted before proceeding to the main analysis. 


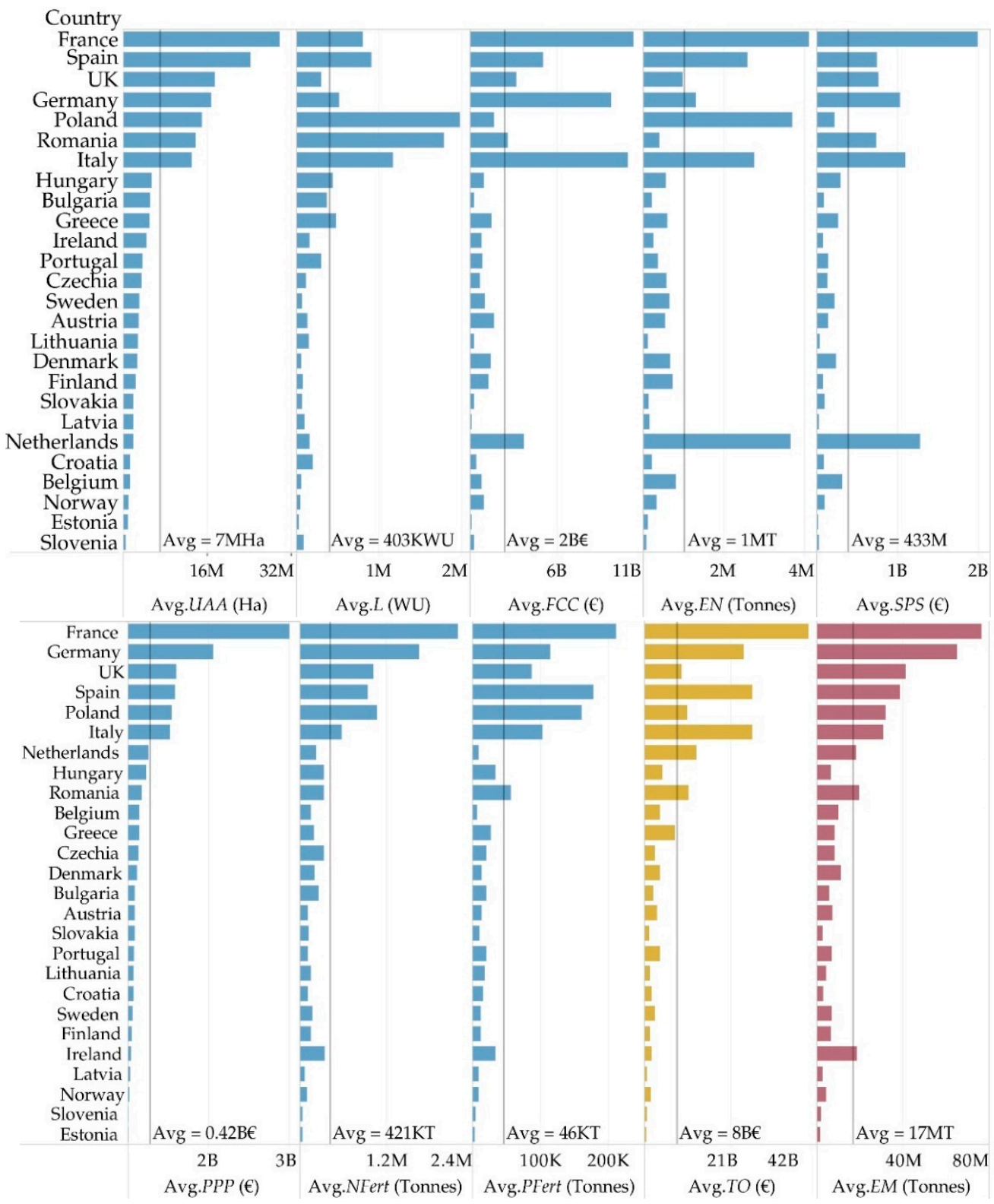

Figure 2. Descriptive statistics of Average Inputs and Outputs per country for reference period 2005-2019.

\subsection{Window DEA Results}

As described in earlier, before proceeding to Window DEA it is essential to identify the ideal window width for this data set. For this purpose, Window DEA was performed for all possible window widths and then results were grouped by year. Using Equation (2) results, Table 4 was constructed. The window width with the least difference from the average score for all possible window widths for a given year was selected. Window Width equals to 7 was selected as the ideal one, due to the fact that it contained the highest amount of absolute minimum difference. 


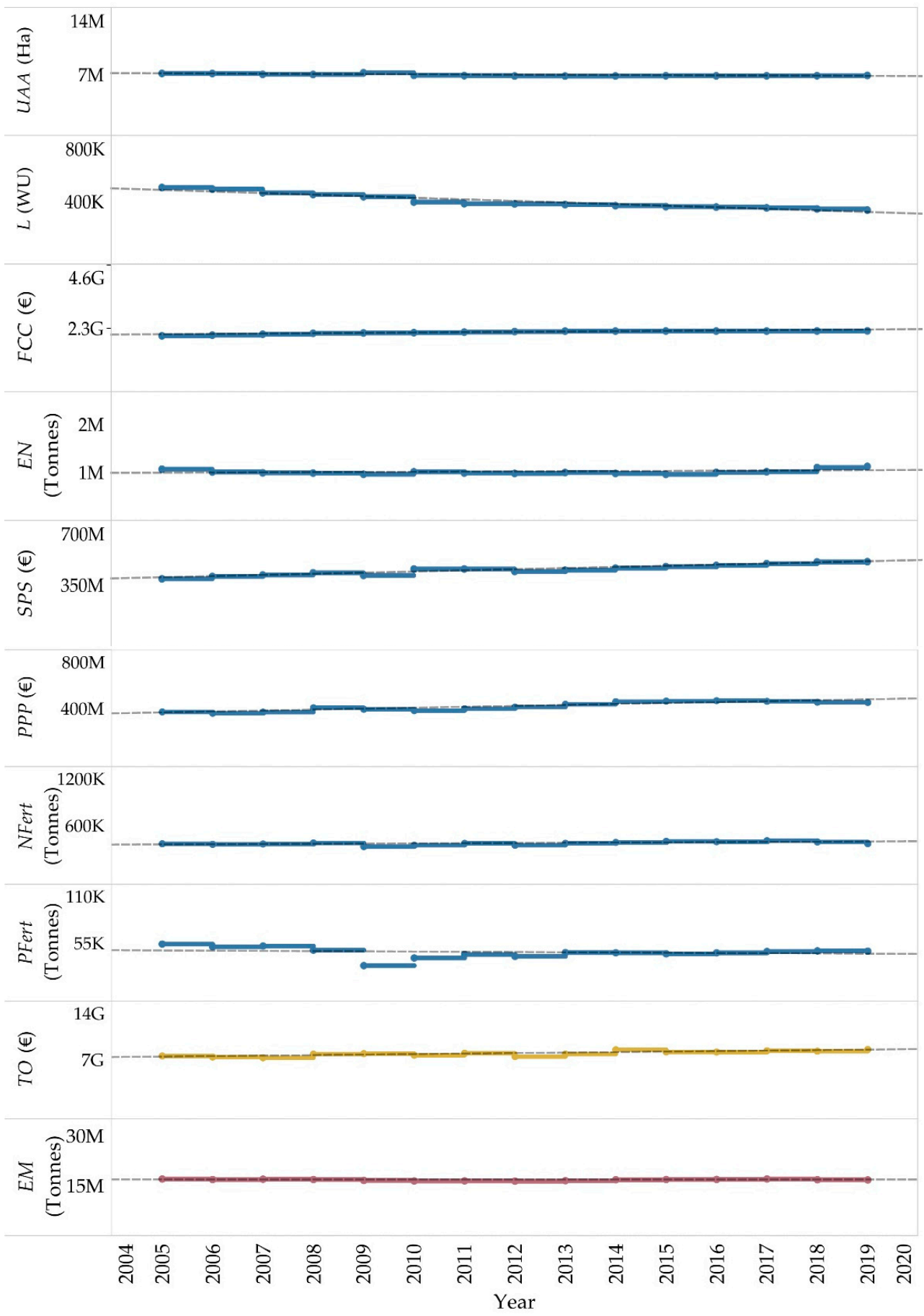

Figure 3. Average valuets of Inputs and Outputs for reference period 2005-2022.

Setting window width equal to 7, Window DEA model was applied. The results of the analysis for $26 \mathrm{EU}$ agricultural sectors are presented in Figure 6. and Table A2 (Appendix A). An assumption of zero technology evolution within frames is made when performing Window DEA. To check the interference of this assumption to the proposed results, a narrower window width has been selected. In this case, an arbitrary window length equals to 4 was chosen in order to identify differences between the widths. Rankings are presenting slightly different results, concluding that technology evolution had a positive impact for the following countries: Greece, Belgium, France, Spain, Portugal, Slovakia, and Ireland. All previous countries confronted serious issues with the financial crisis (20082014) and a narrower window frame can highlight their recovery through technological 
adaptation. Although differences in the climatic conditions which largely affect primary production, Estonia ranks first in comparison with Slovenia which ranks third. The scores of these countries present three points of interest: (1) apart from their relative small size, in comparison with the other EU agricultural sectors, they achieve scores placing them in the top-3 countries, (2) despite their climatic differences Estonia scores higher than Slovenia (3) placement of the Netherlands in the second position assures results validity even in the presence of large scale differences.

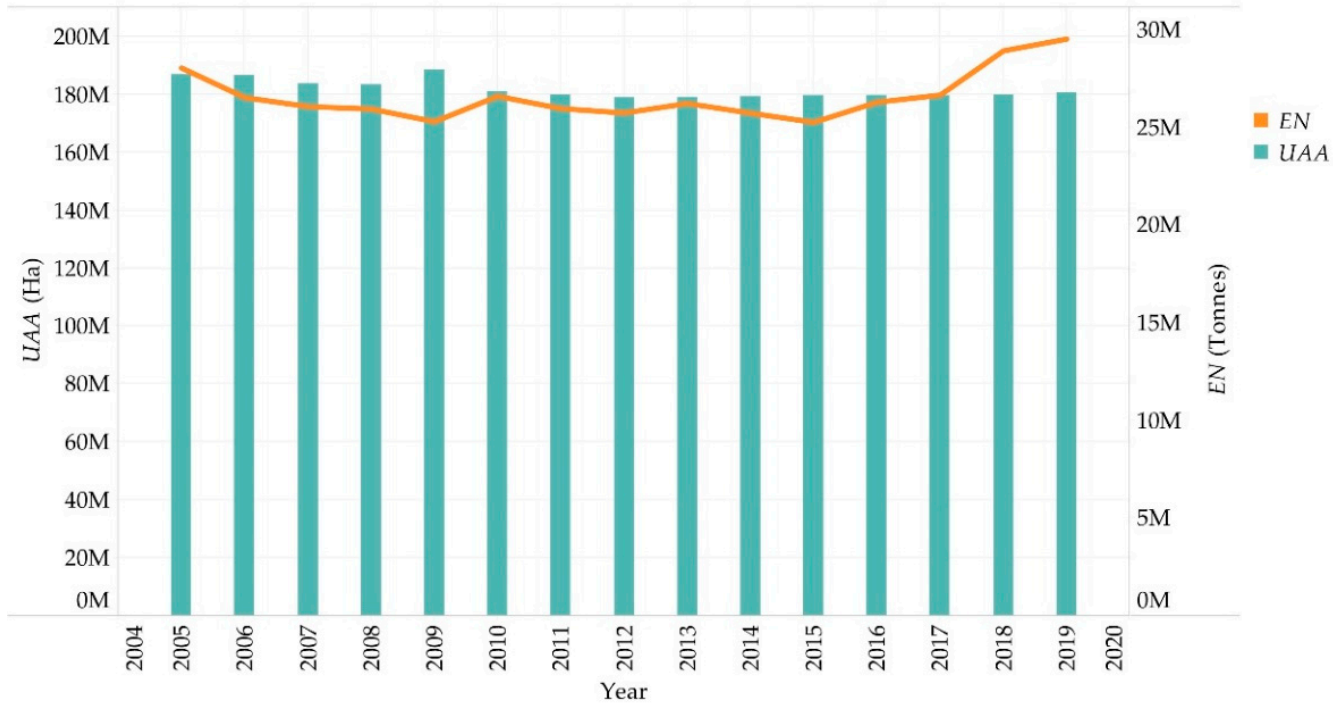

Figure 4. Total Used Agricultural Area $(U A A)$ and Energy consumption in agriculture $(E N)$ for the period 2005-2019.

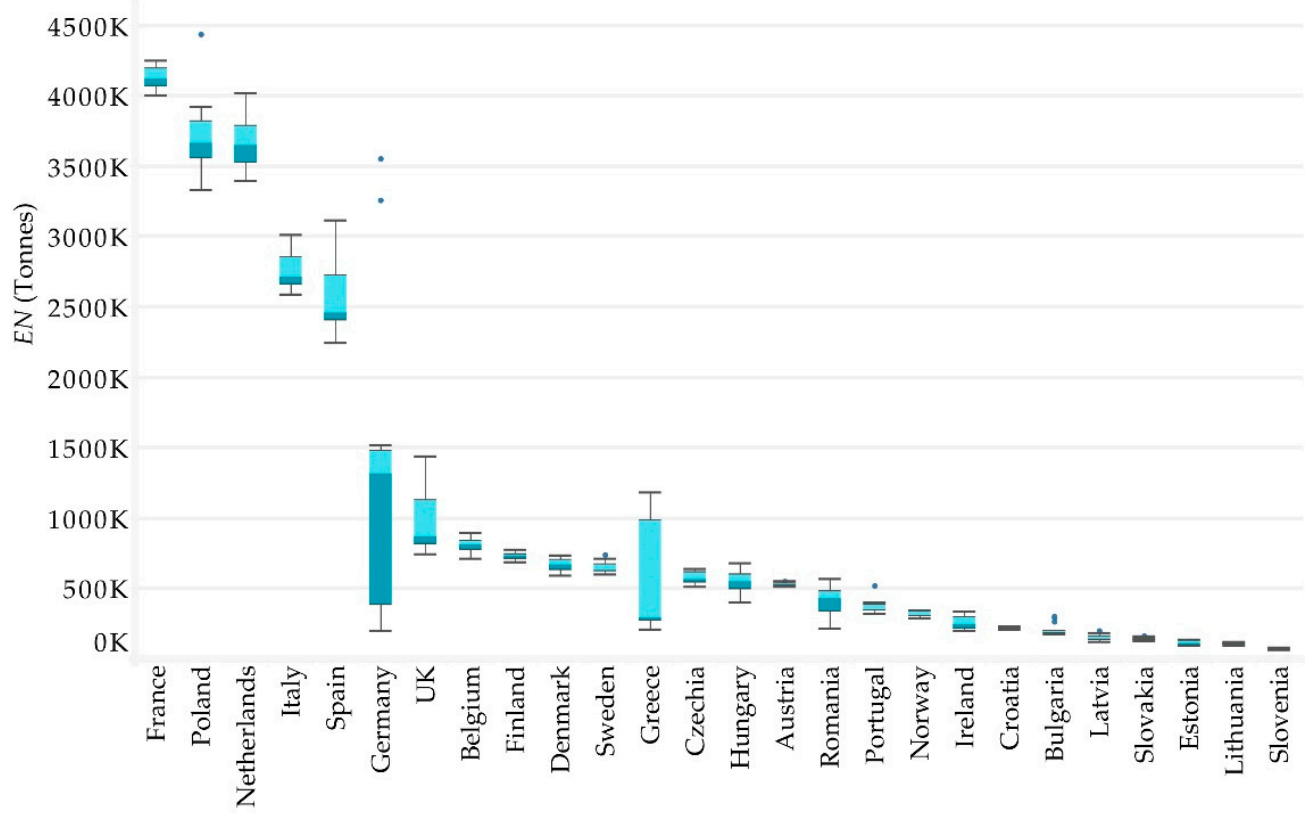

Figure 5. Annual Energy Consumption (EN) per country for the period 2005-2019. 
Table 4. Equation (2) results (absolute values) for all possible window lengths for the reference period 2005-2019.

\begin{tabular}{|c|c|c|c|c|c|c|c|c|c|c|c|c|c|c|c|}
\hline \multicolumn{16}{|c|}{ Possible Window Widths } \\
\hline Year & 1 & 2 & 3 & 4 & 5 & 6 & 7 & 8 & 9 & 10 & 11 & 12 & 13 & 14 & 15 \\
\hline 2005 & 4.9 & 4.4 & 3.8 & 2.7 & 1.7 & 1.3 & 0.3 & 0.4 & 0.7 & 1.6 & 2.1 & 2.8 & 3.0 & 4.0 & 4.5 \\
\hline 2006 & 7.0 & 5.2 & 3.8 & 2.4 & 1.6 & 0.8 & 0.0 & 0.4 & 1.1 & 1.9 & 2.5 & 2.8 & 3.3 & 4.0 & 4.7 \\
\hline 2007 & 8.4 & 6.0 & 4.5 & 2.9 & 1.7 & 0.8 & 0.0 & 0.7 & 1.4 & 2.2 & 2.7 & 3.3 & 3.9 & 4.7 & 5.6 \\
\hline 2008 & 5.5 & 4.3 & 3.7 & 3.0 & 2.1 & 1.3 & 0.5 & 0.4 & 1.1 & 1.8 & 2.4 & 3.0 & 3.4 & 3.9 & 4.5 \\
\hline 2009 & 2.7 & 2.6 & 2.2 & 1.7 & 1.4 & 0.9 & 0.3 & 0.2 & 0.5 & 0.9 & 1.3 & 1.6 & 2.0 & 2.3 & 2.9 \\
\hline 2010 & 6.2 & 4.3 & 3.1 & 2.3 & 1.7 & 1.1 & 0.3 & 0.3 & 0.9 & 1.6 & 2.3 & 2.7 & 3.2 & 3.7 & 4.4 \\
\hline 2011 & 4.8 & 4.0 & 3.0 & 2.3 & 1.5 & 1.0 & 0.5 & 0.2 & 0.7 & 1.4 & 2.0 & 2.5 & 2.9 & 3.3 & 3.9 \\
\hline 2012 & 6.5 & 4.1 & 3.0 & 1.9 & 1.2 & 0.6 & 0.1 & 0.4 & 1.0 & 1.6 & 2.2 & 2.5 & 2.9 & 3.2 & 3.7 \\
\hline 2013 & 4.7 & 3.5 & 2.6 & 2.0 & 1.4 & 0.8 & 0.2 & 0.2 & 0.6 & 1.3 & 1.8 & 2.2 & 2.6 & 3.0 & 3.5 \\
\hline 2014 & 3.1 & 2.3 & 1.7 & 1.3 & 0.8 & 0.4 & 0.2 & 0.1 & 0.3 & 0.6 & 1.1 & 1.4 & 1.7 & 2.1 & 2.5 \\
\hline 2015 & 4.2 & 2.4 & 1.8 & 1.1 & 0.5 & 0.3 & 0.0 & 0.3 & 0.6 & 0.8 & 1.0 & 1.4 & 1.7 & 2.1 & 2.4 \\
\hline 2016 & 4.1 & 2.5 & 1.5 & 1.0 & 0.5 & 0.2 & 0.0 & 0.4 & 0.7 & 0.9 & 1.1 & 1.2 & 1.5 & 1.8 & 2.2 \\
\hline 2017 & 3.5 & 2.0 & 1.2 & 0.7 & 0.4 & 0.2 & 0.1 & 0.1 & 0.4 & 0.7 & 1.0 & 1.1 & 1.2 & 1.6 & 2.0 \\
\hline 2018 & 3.6 & 2.2 & 1.5 & 0.9 & 0.5 & 0.2 & 0.0 & 0.3 & 0.4 & 0.8 & 1.1 & 1.3 & 1.4 & 1.5 & 2.1 \\
\hline 2019 & 2.0 & 1.4 & 1.0 & 0.9 & 0.4 & 0.1 & 0.1 & 0.1 & 0.1 & 0.2 & 0.9 & 1.0 & 1.1 & 1.1 & 1.2 \\
\hline N(MIN) & 0 & 0 & 0 & 0 & 0 & 0 & 10 & 5 & 0 & 0 & 0 & 0 & 0 & 0 & 0 \\
\hline
\end{tabular}

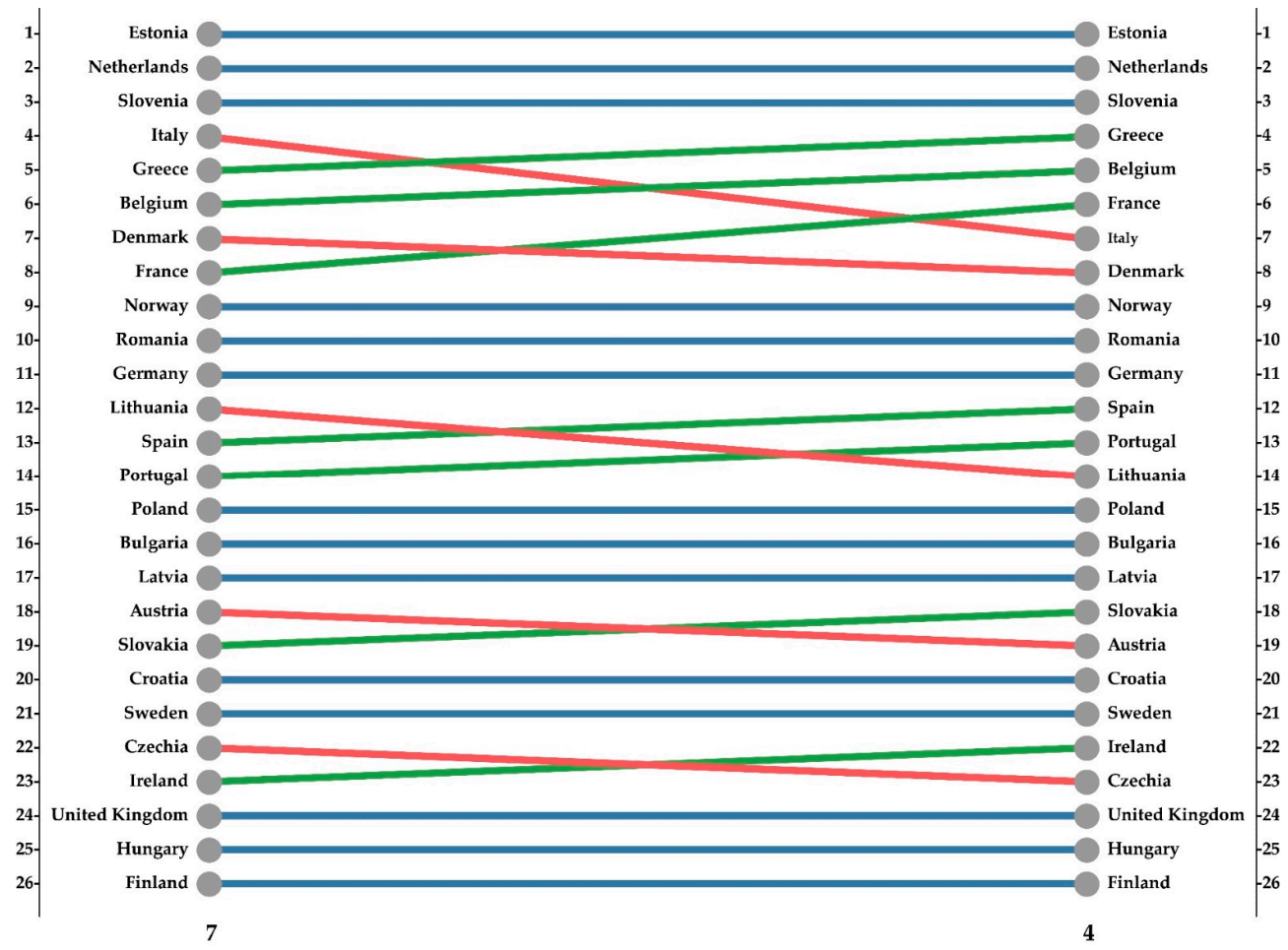

Figure 6. Differences in ranking between Window Width equals to 7 (left) and 4 (right).

\subsection{Projected Efficiency Scores}

Data from 2005 to 2019 for all variables involved were projected to 2022, in order to acquire projected efficiencies. The above-mentioned procedure was followed, estimating the ideal window width and performing DEA Window model. Table 5 indicates that ideal window equals to 9. 
Table 5. Equation (2) results (absolute values) for all possible window lengths for the reference period 2005-2022.

\begin{tabular}{|c|c|c|c|c|c|c|c|c|c|c|c|c|c|c|c|c|c|c|}
\hline \multicolumn{19}{|c|}{ Possible Window Widths } \\
\hline & 1 & 2 & 3 & 4 & 5 & 6 & 7 & 8 & 9 & 10 & 11 & 12 & 13 & 14 & 15 & 16 & 17 & 18 \\
\hline 2005 & 5.9 & 5.4 & 4.8 & 3.7 & 2.8 & 2.3 & 1.3 & 0.6 & 0.3 & 0.7 & 1.1 & 1.8 & 2.0 & 3.0 & 3.6 & 4.0 & 4.9 & 6.1 \\
\hline 2006 & 8.0 & 6.3 & 4.8 & 3.4 & 2.6 & 1.8 & 1.0 & 0.5 & 0.1 & 0.9 & 1.5 & 1.9 & 2.4 & 3.1 & 3.6 & 4.2 & 5.0 & 5.9 \\
\hline 2007 & 9.6 & 7.2 & 5.7 & 4.1 & 2.8 & 1.9 & 1.1 & 0.4 & 0.3 & 1.1 & 1.6 & 2.2 & 2.8 & 3.5 & 4.1 & 4.9 & 5.7 & 6.6 \\
\hline 2008 & 6.6 & 5.4 & 4.8 & 4.1 & 3.1 & 2.4 & 1.5 & 0.7 & 0.0 & 0.7 & 1.4 & 1.9 & 2.5 & 3.2 & 3.9 & 4.4 & 5.0 & 5.6 \\
\hline 2009 & 3.4 & 3.3 & 2.9 & 2.5 & 2.1 & 1.6 & 1.0 & 0.5 & 0.2 & 0.2 & 0.6 & 1.0 & 1.4 & 2.0 & 2.4 & 2.8 & 3.2 & 3.7 \\
\hline 2010 & 7.2 & 5.3 & 4.1 & 3.3 & 2.7 & 2.0 & 1.3 & 0.7 & 0.1 & 0.6 & 1.2 & 1.8 & 2.4 & 3.1 & 3.6 & 4.1 & 4.6 & 5.3 \\
\hline 2011 & 5.7 & 4.7 & 3.9 & 3.1 & 2.4 & 1.8 & 1.3 & 0.7 & 0.1 & 0.4 & 1.0 & 1.7 & 2.1 & 2.7 & 3.2 & 3.7 & 4.1 & 4.8 \\
\hline 2012 & 7.4 & 4.8 & 3.9 & 2.7 & 2.0 & 1.4 & 1.0 & 0.5 & 0.1 & 0.7 & 1.3 & 1.8 & 2.2 & 2.7 & 3.1 & 3.5 & 3.9 & 4.5 \\
\hline 2013 & 5.6 & 4.4 & 3.8 & 2.9 & 2.2 & 1.6 & 1.1 & 0.6 & 0.1 & 0.6 & 1.2 & 1.6 & 2.0 & 2.5 & 2.9 & 3.3 & 3.8 & 4.5 \\
\hline 2014 & 4.1 & 3.2 & 2.6 & 2.3 & 1.8 & 1.3 & 0.9 & 0.4 & 0.0 & 0.3 & 0.7 & 1.0 & 1.4 & 1.8 & 2.1 & 2.6 & 3.0 & 3.7 \\
\hline 2015 & 5.1 & 3.3 & 2.7 & 2.0 & 1.6 & 1.1 & 0.6 & 0.1 & 0.2 & 0.4 & 0.7 & 1.0 & 1.4 & 1.8 & 2.1 & 2.4 & 2.9 & 3.5 \\
\hline 2016 & 5.0 & 3.4 & 2.4 & 1.8 & 1.3 & 1.0 & 0.5 & 0.0 & 0.4 & 0.6 & 0.8 & 0.9 & 1.3 & 1.7 & 2.0 & 2.2 & 2.5 & 3.0 \\
\hline 2017 & 4.4 & 2.9 & 2.0 & 1.5 & 1.0 & 0.6 & 0.5 & 0.2 & 0.1 & 0.3 & 0.6 & 0.7 & 0.9 & 1.4 & 1.7 & 2.0 & 2.4 & 3.0 \\
\hline 2018 & 4.5 & 3.1 & 2.2 & 1.6 & 1.1 & 0.7 & 0.3 & 0.2 & 0.2 & 0.5 & 0.8 & 1.0 & 1.1 & 1.3 & 1.7 & 2.0 & 2.3 & 2.9 \\
\hline 2019 & 3.0 & 2.3 & 1.7 & 1.2 & 0.8 & 0.6 & 0.3 & 0.0 & 0.1 & 0.1 & 0.5 & 0.7 & 0.8 & 1.0 & 1.1 & 1.4 & 1.9 & 2.5 \\
\hline 2020 & 3.2 & 2.1 & 1.3 & 1.0 & 0.7 & 0.4 & 0.0 & 0.2 & 0.4 & 0.2 & 0.5 & 0.6 & 0.7 & 0.8 & 0.9 & 1.0 & 1.5 & 2.1 \\
\hline 2021 & 2.4 & 1.8 & 1.3 & 0.8 & 0.6 & 0.4 & 0.0 & 0.3 & 0.3 & 0.4 & 0.3 & 0.5 & 0.6 & 0.7 & 0.8 & 0.8 & 0.9 & 1.6 \\
\hline 2022 & 1.6 & 1.5 & 1.3 & 0.7 & 0.5 & 0.3 & 0.1 & 0.2 & 0.3 & 0.3 & 0.4 & 0.5 & 0.5 & 0.6 & 0.7 & 0.8 & 0.8 & 1.0 \\
\hline $\begin{array}{l}\text { Total } \\
\text { MINs }\end{array}$ & 0 & 0 & 0 & 0 & 0 & 0 & 3 & 4 & 11 & 0 & 0 & 0 & 0 & 0 & 0 & 0 & 0 & 0 \\
\hline
\end{tabular}

Analysis was performed with window width 9 and another two sub groups of 3 and 6 have been tested in order to minimize the effect of zero technological improvement (Figure 7 and Table A3). The four highest ranking countries remained the same for all widths examined. The same situation is depicted for Finland, the UK, and Hungary, which achieved the lowest efficiency scores in all estimated widths. A very interesting case in the following benchmarking is this of Italy, in which position is downgraded (5 -> 8) in window width 9 compared to 6 and upgraded from $8->6$ when window is being shorten to three years. Constant technological improvement seems to affect Norway's performance, due to the fact that its rankings are higher and higher between nine and three-year frame.

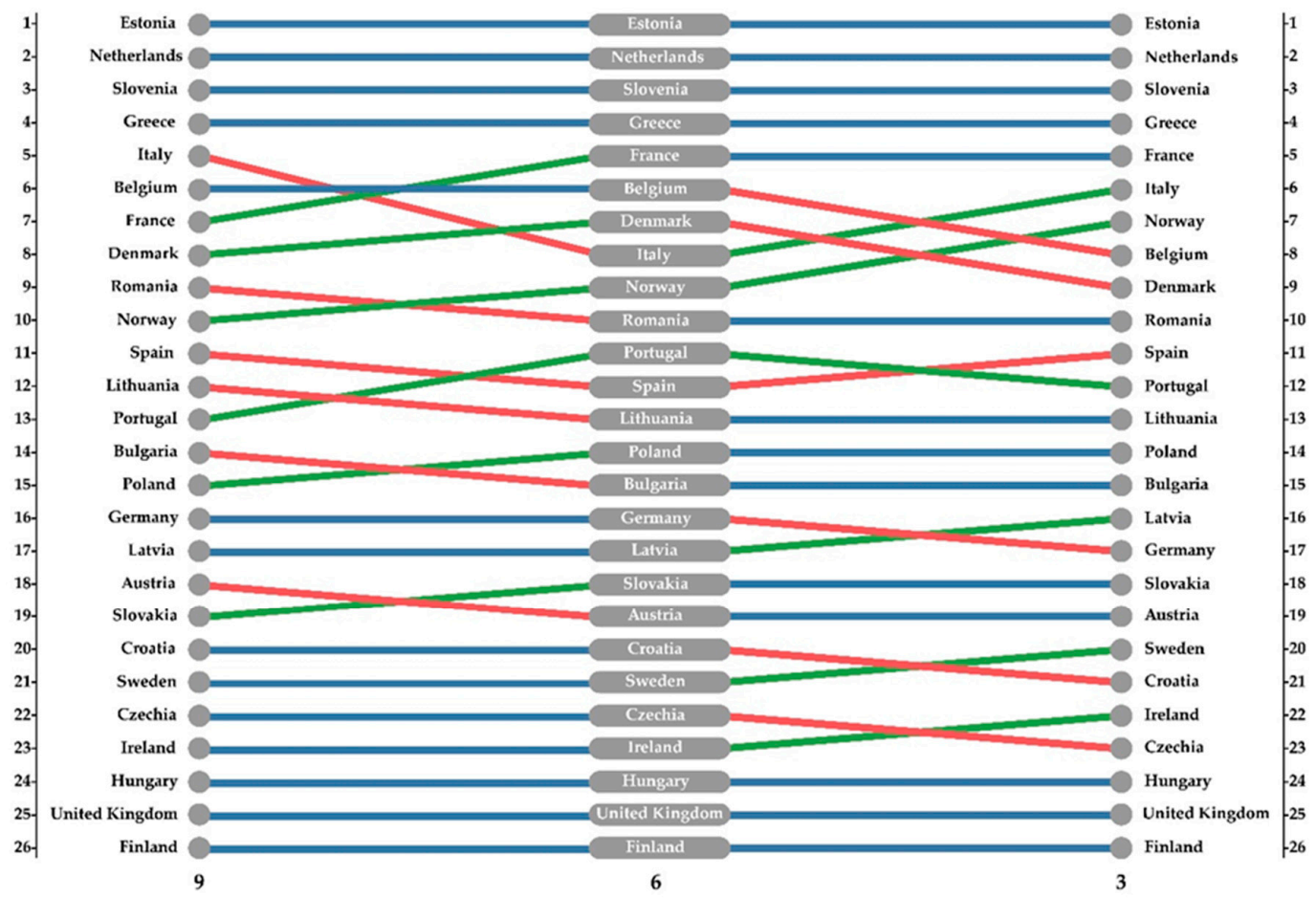

Figure 7. Differences in ranking between Window Width equals to 9 (left), 6 (center) and 3 (right) for projected data. 
For visualization purposes, Figures 8 and 9 were created so as to depict the efficiency scores achieved for each country from DEA Window analysis ideal window widths 7 and 9 for periods 2005-2019 and 2005-2022, accordingly. Lower efficiency scores can be observed on central EU countries (Austria, Czech Rep., Hungary, and Croatia) and Finland presents the lower performance. Only few changes occurred between projected and non-projected efficiency scores. Projected data reveal higher efficiency scores for Greece, France, Romania, Spain, Portugal, Bulgaria, and Hungary for the next three years. Italy, Denmark, Norway, Germany, and UK obtained lower efficiency scores underlying the urge for changes in their agricultural sectors, regarding all inputs involved in agricultural production. The greatest difference in the ranking system is for the agricultural domain of Germany, which falls from place 11 for actual data to place 16 for the projected data.

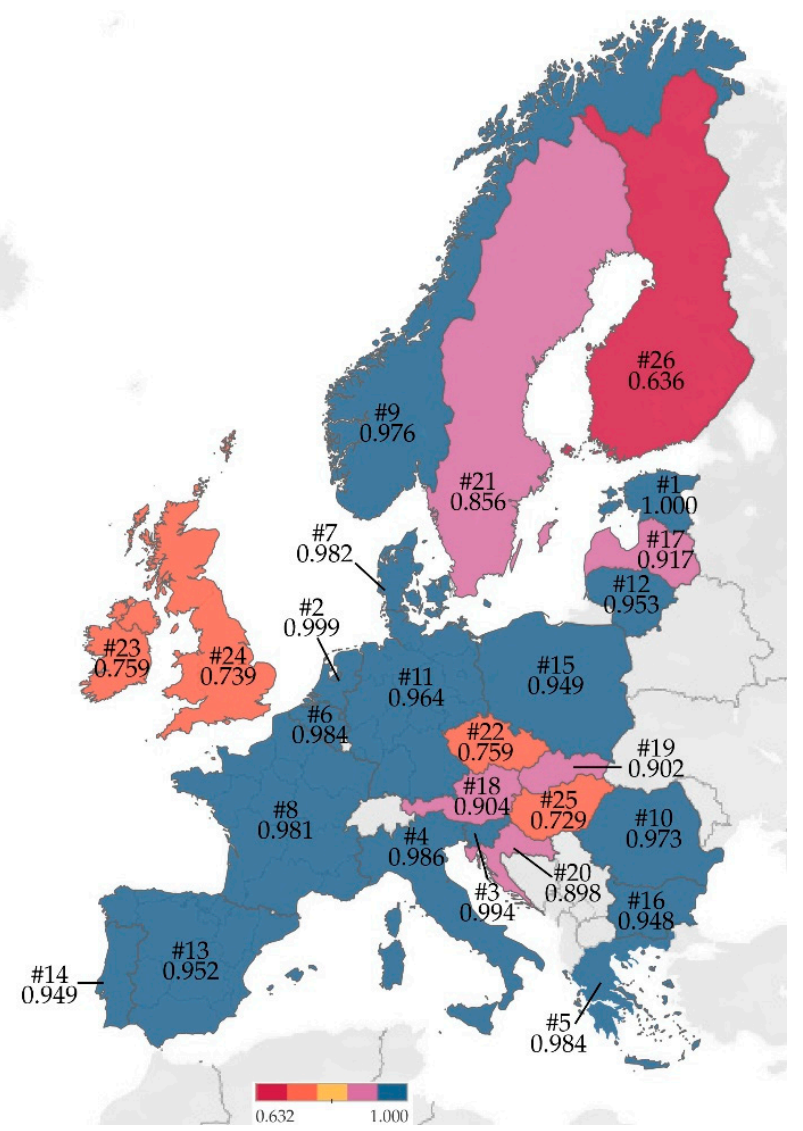

Figure 8. Efficiency scores map, Window Width (7) (2005-2019). 


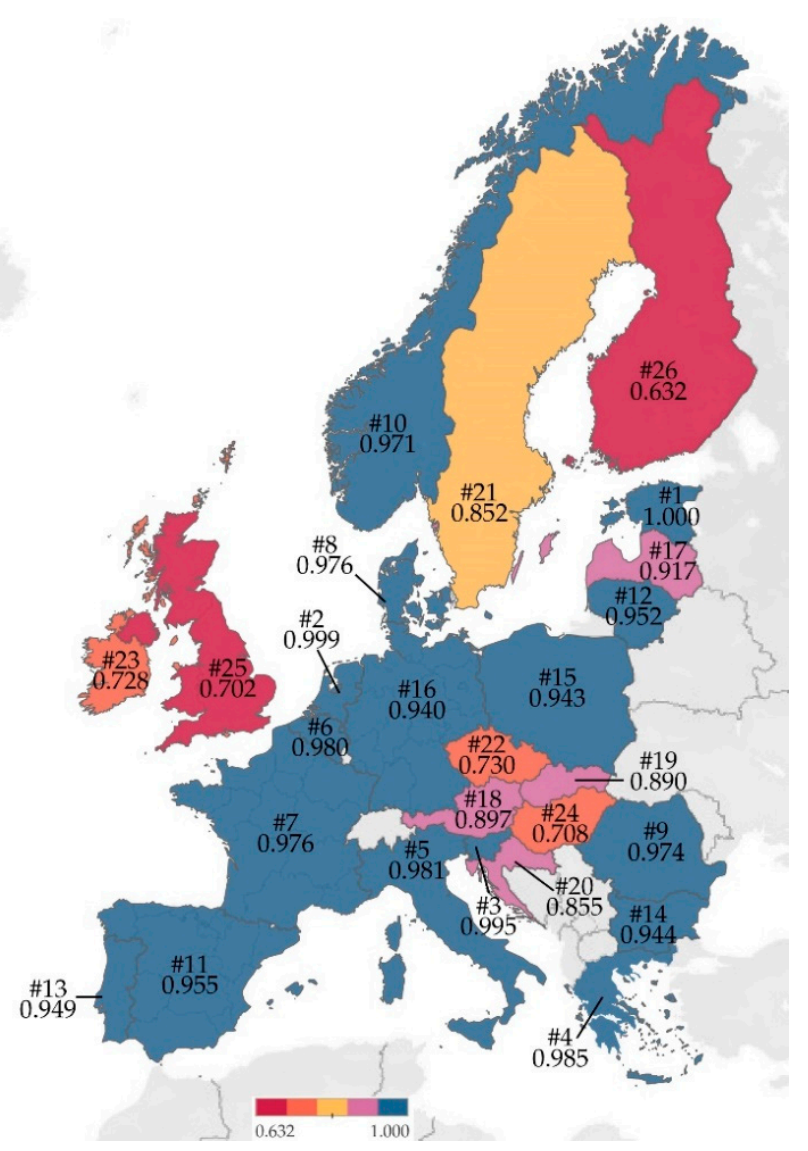

Figure 9. Efficiency scores map, Window Width (9) (2005-2022).

\section{Discussion}

The main objective of this study was to assess input use efficiency for all EU countries involved after the implementation of AGENDA 2000, assuring the validity of Window DEA methodology and clarifying the influence of window width in the results obtained. Major goal of Agenda 2000 was to set the base for increased efficiencies of small and medium enterprises (SMEs) in agriculture, leading to more competitive EU primary sectors [71]. According to Agenda 2000, new technologies engagement was the key factor for improving performance of European agriculture. Following the upcoming evolution of Agenda 2000 and CAP (2014-2020), in the new CAP programing period (2021-2027) the main strategy is based on the same objectives, focusing even more on applying specific environmental indicators for assessing performance of agricultural holdings. This is the rationale for the Integrated Farm Management (IFM) approach, defining the equilibrium between economy, environment and society [72]. On operational terms, IFM proposes the minimum use of every input, reducing the overall cost and enhancing environmental protection. Taking into consideration the above-mentioned approach, the DEA model was used with an input orientation, aiming to assess in a quantified manner the efficiency distances among EU countries, while the use of Window DEA presented in a graphical manner the evolution of efficiencies for the specific time period. However, it should be clarified that through the assessment of alternative window lengths, technology influence has been revealed as an important factor for achieving efficient use of both energy and non-energy related inputs in agriculture.

Ideal window width estimation has been calculated for creating a reference point where according to methodology, technological change is apparent. Further limiting of window widths leads to the emergence of countries that have adopted new changes in a shorter period of time and these changes had an impact on the overall way they use their 
inputs. For this reason, even ideal window frame has been calculated for 7 and 9 years accordingly, smaller window frames have been selected, pinpointing differences due to the aforementioned assumption.

Window DEA has the unique feature of using the same DMU multiple times in the same window, being considered to be a different one. Benchmarking of agricultural sector regarding crop production highlighted that Estonia, the Netherlands, Slovenia, Greece, and Italy have the best performance, while Finland, UK and Hungary should reconsider their inputs' usage. The results of this analysis have been compared with previous survey examining eco-efficiency in agricultural sectors of EU countries with as base year 2015 [45]. Similar results been exported despite the fact that previous stages of LCA have been performed. A point of particular interest is that Bulgaria and Romania were characterized as environmentally friendly, but presented decreased economic performance. In this study, where both environmental and economic factors consist this model, Romania and Bulgaria achieve moderate scores. Another great remark is the difference in ranks between agricultural sectors of common input and output characteristics (Estonia (1) and Slovenia (3)), despite the negative impact of climatic conditions for the first one. Validity of the results between agricultural sectors with moderate scale differences is proven, due to the fact that the Netherlands, which handles much greater amounts of inputs and outputs from Slovenia and Estonia, ranks second.

Both the literature review $[17,24]$ and descriptive statistics revealing the need for further training and information in the agricultural sector regarding energy minimization. Despite the efforts of the EU to mitigate energy consumption in agriculture, it seems that only very few changes have occurred in recent decades. As Eurostat's data reveal, there is a $5 \%$ increase in energy, while total used agricultural area has a slight decrease of $3 \%$. Overall energy consumption should have been dropped, due to the increased energy efficiency of technological equipment and the need for minimizing agricultural expenditures and environmental impact. It should be also pointed out that share of renewable energy sources has not changed for the last two decades, while amounts of fertilizers have remained stable for the examined period. This fact should be severely considered from policy makers, linking payments with energy efficiency for farmers' side, leading to minimized production needs for fertilizer industry. Skjærseth states that European Commission should gain a higher level of control from member states in order to achieve sustainable goals of 2050, leading to minimized energy exploitation and limited GHG emissions [73].

Figure 4 indicates a geographical pattern, where neighboring countries of central Europe achieve lower scores than the others. The comparison of results obtained from past studies $[13,41]$ with the results of this one, lead to the need for further studies to clarify the reasons which lead to lower efficiency use of inputs involved in agricultural production. Factors such as climate conditions, support on a national level, by providing sufficient financial and administrational aid, and farm structure characteristics should be taken into consideration.

Risk management in case of extreme weather conditions and environmental protection are highly considered in the upcoming CAP (2021-2027). Thus, there is lack of data regarding the quality and quantity of the equipment used on a national level for agricultural production, and R\&D support. Emphasis should be given in the amounts of water used for irrigation. Although the existence of data referring to irrigated agricultural area and water exploitation index is confirmed, monitoring of amounts consumed remains insufficient on EU level, taking also into consideration that agriculture is the greater water consumer [74]. All the above-mentioned factors are crucial for effective benchmarking and targeted decision making for each EU country.

It is very prominent that European Commission has just released a dedicated webpage to energy consumption indicating the enhanced importance for energy monitoring. It referred that the overall energy dependency of EU is around 60\% (2018) [75], while 1 out of 3 crude oil barrels comes from Russia. Moreover, energy efficiency results are displayed for every EU country, but the results are not linked to the agricultural domain. An addition of 
energy use efficiency per sector is proposed both for the information of the public but also for immediate comparisons among EU countries.

Sustainable Development Goals and especially those referring to food security, sustainable production, and climate change mitigation (SDG2, 12, 13) have to be adopted from all EU countries. Climate change already has various effects on agricultural production, creating new geographical pattern both for productive species and their pests. Assuring that every EU country can produce with high efficiency input use rates, resilience can be built up for all member states, especially under the existence of unpredictable phenomena such as prolonged drought, very low temperatures, or a potential increase in prices of imported inputs from non-EU countries.

\section{Conclusions}

To conclude, an alternative method for prognosticate future efficiency scores is proposed. Window DEA has been performed multiple times, assessing differences between various window widths and reference periods. From an academic point of view this paper, provides multiple nested comparisons between actual and projected data. Differences between optimal window width and arbitrary chosen window length have been highlighted. Due to the fact that DEA is a benchmarking technique, emphasis has been given in the final rank of each EU agricultural sector and not in the actual values of efficiency scores. It has been notified several times in this paper that researchers should be aware of the assumption of zero technological change within frames, when performing Window DEA; for this reason, window width should be resized accordingly. This need becomes more apparent when dealing with large time series when window width selection can influence final rankings. A possible limitation of this survey, regarding future projections, is its actual dataset. For instance, EUROSTAT database had a panel of full data from 2005 until 2019. To assure projections' validity, only a 3-year period time data have been forecasted. With a larger dataset, a projection of an elongated period would have been possible and maybe a larger variation in the rankings between actual and projected data would be apparent.

Implication of the results signify differences between alternative window widths, meaning that external factors within frame had influence on input use efficiency of the examined countries. Moreover, projected data have been calculated by identifying 2019 as the ending year of the dataset. Few changes occurred between projected and nonprojected efficiency scores, underlying the need for the following countries: Czech Republic, Finland, Ireland, Hungary, and the UK should reconsider their production protocols and the usage of their production factors. Despite the fact that this survey has pointed out the above-mentioned countries as the least efficient, a following analysis is needed in order to highlight the inefficiencies of each variable leading to more applicable results. Thus, it should be stated that this paper's goal was mostly to identify differences between different window widths rather than focusing on DEA slacks. Results indicate the importance of continuous monitoring, so as to assure sustainable exploitation of the involved inputs, mainly regarding energy consumption. Figures 8 and 9 pinpoint lower efficiency scores for countries of central Europe Austria, Czech Republic, Hungary, and Croatia, meaning that they should be supported accordingly. It should not be neglected that the above-mentioned countries will have to restrain climate change effects, partially replacing the production of Mediterranean countries such as Italy, Spain, and Greece. For this reason, emphasis should be given on the development of their agricultural sectors, maintaining low emission levels at the same time. Moreover, ranking differences for Germany, between actual and projected data, should act as a warning notification. Projected data are referring to an extra 3-year period time, which can be considered to be a short one for large changes in agricultural sector.

Future studies can focus on the infrastructures of EU agricultural sectors defining the variables that mostly affect the extracted results, giving insights for every agricultural sector in order to clarify the reasons which affect most efficiency shortage (e.g., lack of information, aged population, soil of decreased productivity, climatic conditions etc.). 
In addition, this paper has an on farm approach while future studies can implement Window DEA methodology in whole supply chains. Energy use in packaging, storage and transportation will largely affect the extracted results, providing an overall inputs use efficiency from farm to fork. Additionally, technological evolution will bring more changes for arable land crops and greenhouse farming, gradually decreasing the need for human labor but increasing the need for energy use.

In the present paper, energy use factor affected the extracted results both directly as an input, but also indirectly with the use of fertilizers and GHG emissions. Energy prices influence immediately the primary production by increasing the cost of all inputs involved. A combination of the results with Skjærseth statements (Discussion section) [73] will enhance the argument of augmented control from national sectors, in order to deal with their challenges in local level. Benefits for greater input use efficiencies can be provided, in order to motivate more individuals or groups in this direction. Given the fact that energy dependency of EU is high [75], measures that assure energy security in the agricultural sector should be taken, in order to prevent future energy instability situations such as the case of Russia-Ukraine gas disputes. Extensive on-farm use of sensors technology will permit the accurate data recording and monitoring, leading in optimized decisions for everyday tasks and it will also provide insights for policy making both on national and European level, in order to achieve greater energy use efficiency. Moreover, Perpiña Castillo et al. survey states the remarkable dynamic for establishment of large scale photovoltaic systems in Southern European countries regarding sunlight, population distance, land use, morphological characteristics and policy [76]. It should be underlined that implementation of solar power generation could be a great alternative for covering EU countries energy needs while preserving natural resources from exploitation.

Cost parameter regarding energy use is very crucial due to the fact that it affects both in a direct (oil, electricity, gasoline) or in an indirect way inputs such as fertilizers, agro-chemicals, or transportation costs. As it is stated in the latest European Report about energy prices, share of energy costs in fertilizers' industry is 71\% [77]. Furthermore, it can immediately influence supply and demand curves leading to either increased or decreased consumption. However, pricing strategies applied by agrochemical industries are not usually based on production costs but in a close relation with the upcoming benefits derived from their use. Therefore, we assume that energy cost is still an important parameter for the overall production cost in every European country, being at the same time a top priority target for the significant reduction of it for both operational and environmental purposes.

Furthermore, agricultural inputs have to be limited preventing degradation of natural resources and mitigating environmental consequences. To conclude, all the abovementioned parameters should be taken into consideration from EU countries for the upcoming CAP (2021-2027), so as to adjust their national strategies and achieve Sustainable Development Goals.

Author Contributions: Conceptualization, G.V. and P.M.P.; methodology, G.V.; software, L.S.K.; validation, G.V. and P.M.P.; formal analysis, L.S.K.; investigation, L.S.K.; resources, L.S.K.; data curation, L.S.K.; writing — original draft preparation, L.S.K.; writing — review and editing, G.V. and P.M.P.; visualization, G.V.; supervision, P.M.P. All authors have read and agreed to the published version of the manuscript.

Funding: This research received no external funding.

Institutional Review Board Statement: Not applicable.

Informed Consent Statement: Not applicable.

Data Availability Statement: The data presented in this study are openly available in Centre of Open Science at http:/ / doi.org/10.17605/OSF.IO/RS8EK.

Conflicts of Interest: The authors declare no conflict of interest. 


\section{Appendix A}

Table A1. Descriptive statistics of Inputs and Outputs for reference period 2005-2022.

\begin{tabular}{|c|c|c|c|c|c|c|c|c|c|c|c|}
\hline Year & & $U A A$ & $L$ & $C C$ & $E N$ & SPS & $P P P$ & NFert & PFert & TO & $E M$ \\
\hline & Min & 511 & 37.8 & 49.3 & 75.1 & 5.7 & 6.9 & 20,083 & 2743 & 272 & 1194 \\
\hline \multirow{3}{*}{2005} & Max & 29,588 & 2596 & 10,189 & 4438 & 1952 & 2742 & $2,346,289$ & 300,652 & 39,435 & 77,314 \\
\hline & Avg. & 7182 & 492 & 2050 & 1077 & 383 & 377 & 417,244 & 54,076 & 7521 & 17,074 \\
\hline & Min & 491 & 37.4 & 58.2 & 75.4 & 5.7 & 7.1 & 22,610 & 3536 & 229 & 1193 \\
\hline \multirow[t]{3}{*}{2006} & Max & 32,346 & 2527 & 32,345 & 4130 & 1929 & 2676 & $2,163,040$ & 258,427 & 38,280 & 76,913 \\
\hline & Avg. & 7175 & 482.3 & 482.3 & 1019.7 & 396.0 & 368.2 & 411,693 & 51,577 & 7393 & 16,912 \\
\hline & Min & 498 & 32.9 & 67.4 & 74.4 & 7.4 & 10.1 & 24,982 & 3520 & 316 & 1251 \\
\hline \multirow[t]{3}{*}{2007} & Max & 29,414 & 2299 & 29,413 & 4032 & 2005 & 2821 & $2,198,141$ & 243,318 & 38,810 & 77,811 \\
\hline & Avg. & 7070 & 458 & 458 & 1002 & 404 & 375 & 415,116 & 52,235 & 7305 & 17,019 \\
\hline & Min & 492 & 31.2 & 77.0 & 76.4 & 10.6 & 13.2 & 25,039 & 4187 & 289 & 1309 \\
\hline \multirow[t]{3}{*}{2008} & Max & 29,385 & 2299 & 10,320 & 4119 & 2076 & 3148 & $2,425,221$ & 282,425 & 40,125 & 78,496 \\
\hline & Avg. & 7060 & 447 & 2143 & 997 & 416 & 406 & 425,737 & 48,340 & 7743 & 16,916 \\
\hline & Min & 469 & 29.3 & 82.2 & 66.3 & 11.2 & 10.6 & 27,328 & 2471 & 299 & 1252 \\
\hline \multirow{3}{*}{2009} & Max & 35,178 & 2213 & 10,305 & 4206 & 1992 & 2997 & $2,098,801$ & 163,851 & 41,119 & 77,674 \\
\hline & Avg. & 7258 & 433 & 2156 & 972 & 401 & 395 & 388,395 & 33,785 & 7798 & 16,664 \\
\hline & Min & 483 & 25.4 & 82.4 & 69.5 & 14.7 & 15.6 & 27,486 & 2671 & 275 & 1278 \\
\hline \multirow[t]{3}{*}{2010} & Max & 29,311 & 1914 & 10,270 & 4121 & 2016 & 2755 & $2,080,333$ & 177,025 & 39,164 & 76,456 \\
\hline & Avg. & 6957 & 399 & 2165 & 1022 & 437 & 386 & 402,166 & 40,991 & 7611 & 16,488 \\
\hline & Min & 458 & 24.4 & 85.2 & 67.5 & 16.4 & 16.3 & 27,134 & 2680 & 311 & 1294 \\
\hline \multirow[t]{3}{*}{2011} & Max & 28,853 & 1914 & 10,449 & 4141 & 2220 & 2754 & $2,332,390$ & 218,428 & 40,235 & 75,763 \\
\hline & Avg. & 6927 & 389 & 2186 & 998 & 437 & 399 & 421,528 & 44,329 & 7844 & 16,507 \\
\hline & Min & 480 & 23.2 & 92.0 & 71.0 & 17.3 & 18.3 & 26,300 & 2955 & 348 & 1375 \\
\hline \multirow[t]{3}{*}{2012} & Max & 29,001 & 1914 & 10,648 & 4014 & 2236 & 2951 & $2,024,929$ & 189,633 & 39,632 & 75,656 \\
\hline & Avg. & 6882 & 387 & 2206 & 989 & 423 & 410 & 402,175 & 42,477 & 7448 & 16,435 \\
\hline & Min & 479 & 22.3 & 101.0 & 70.0 & 20.9 & 19.0 & 27,263 & 3129 & 352 & 1407 \\
\hline \multirow[t]{3}{*}{2013} & Max & 28,976 & 1937 & 10,653 & 4247 & 2084 & 3125 & $2,143,821$ & 217,184 & 39,185 & 75,170 \\
\hline & Avg. & 6878 & 383 & 2222 & 1008 & 430 & 430 & 422,080 & 46,067 & 7,745 & 16,568 \\
\hline & Min & 482 & 22.0 & 100.9 & 75.3 & 21.8 & 19.7 & 28,612 & 3775 & 375 & 1446 \\
\hline \multirow[t]{3}{*}{2014} & Max & 28,930 & 1937 & 10,508 & 4185 & 2262 & 3222 & $2,190,930$ & 206,798 & 43,218 & 77,204 \\
\hline & Avg. & 6890 & 376 & 2223 & 989 & 441 & 448 & 431,685 & 45,887 & 8264 & 16,860 \\
\hline & Min & 477 & 20.3 & 100.9 & 74.2 & 26.2 & 19.7 & 28,319 & 3522 & 451 & 1446 \\
\hline \multirow[t]{3}{*}{2015} & Max & 29,115 & 1937 & 10,493 & 4211 & 2460 & 3235 & $2,208,168$ & 187,054 & 41,554 & 76,992 \\
\hline & Avg. & 6912 & 369 & 2226 & 971 & 450 & 451 & 442,059 & 44,896 & 7997 & 16,927 \\
\hline & Min & 478 & 20.3 & 107.4 & 73.4 & 24.4 & 21.1 & 27,095 & 3444 & 323 & 1402 \\
\hline \multirow[t]{3}{*}{2016} & Max & 29,089 & 1675 & 10,417 & 4086 & 2433 & 3308 & $2,221,231$ & 191,677 & 37,653 & 75,753 \\
\hline & Avg. & 6903 & 367 & 2224 & 1010 & 456 & 454 & 438,584 & 45,836 & 7989 & 16,942 \\
\hline & Min & 481 & 20.3 & 111.0 & 72.9 & 29.5 & 21.5 & 27,084 & 3988 & 383 & 1443 \\
\hline \multirow[t]{3}{*}{2017} & Max & 29,101 & 1675 & 10,352 & 4003 & 2357 & 3063 & $2,248,277$ & 190,414 & 40,501 & 76,190 \\
\hline & Avg. & 6905 & 362 & 2223 & 1024 & 466 & 449 & 448,763 & 47,084 & 8144 & 17,080 \\
\hline & Min & 478 & 20.1 & 113.1 & 74.5 & 28.1 & 20.8 & 27,293 & 4062 & 315 & 1438 \\
\hline \multirow[t]{3}{*}{2018} & Max & 29,020 & 1675 & 10,312 & 4082 & 2392 & 3093 & $2,141,553$ & 190,597 & 40,967 & 74,774 \\
\hline & Avg. & 6918 & 355 & 2226 & 1111 & 475 & 443 & 435,668 & 47,694 & 8092 & 16,865 \\
\hline & Min & 480 & 18.9 & 127.8 & 73.8 & 26.7 & 19.4 & 28,048 & 3538 & 483 & 1457 \\
\hline \multirow[t]{3}{*}{2019} & Max & 29,024 & 1675 & 10296 & 4050 & 2486 & 3092 & $2,130,800$ & 185,252 & 40,637 & 74,573 \\
\hline & Avg. & 6946 & 347 & 2231 & 1134 & 477 & 442 & 418,517 & 47,456 & 8292 & 16,804 \\
\hline & Min & 482 & 18.8 & 122.1 & 73.2 & 25.2 & 17.7 & 27,219 & 3421 & 427 & 1472 \\
\hline \multirow[t]{3}{*}{2020} & Max & 28,678 & 1643 & 10,240 & 4069 & 2511 & 3076 & $2,167,584$ & 335,222 & 40,804 & 74,284 \\
\hline & Avg. & 6940 & 340 & 2235 & 1143 & 484.5 & 441.8 & 420,848 & 54,225 & 8334 & 16,779 \\
\hline & Min & 482 & 18.0 & 125.4 & 72.8 & 23.5 & 15.3 & 27,174 & 2602 & 439 & 1486 \\
\hline 2021 & Max & 28,556 & 1610 & 10,253 & 41,22 & 2535.1 & 3077 & $2,167,076$ & 389,930 & 40,875 & 73,995 \\
\hline & Avg. & 6939 & 331.9 & 2242 & 1162 & 488.8 & 442.6 & 420,572 & 56,972 & 8414 & 16,755 \\
\hline & Min & 482 & 17.2 & 128.7 & 49.3 & 21.8 & 12.9 & 27130 & 1783 & 451 & 1500 \\
\hline 2022 & Max & 28,434 & 1577 & 10,266 & 4417 & 2559 & 3078 & $2,166,569$ & 444,639 & 40,947 & 73,707 \\
\hline & Avg. & 6938 & 323 & 2248 & 1180 & 493 & 443 & 42,0296 & 59,720 & 8494 & 16,730 \\
\hline
\end{tabular}

Table A2. Window analysis results with different window width for the reference period 2005-2019.

\begin{tabular}{ccccc}
\hline & \multicolumn{2}{c}{ Win(4) } & \multicolumn{2}{c}{ Win(7) } \\
\hline & Country & Value & Country & Value \\
\hline 1. & Estonia & 0.9999 & Estonia & 0.9998 \\
\hline 2. & Netherlands & 0.9999 & Netherlands & 0.9995 \\
\hline
\end{tabular}


Table A2. Cont.

\begin{tabular}{|c|c|c|c|c|}
\hline & \multicolumn{2}{|c|}{ Win(4) } & \multicolumn{2}{|c|}{ Win(7) } \\
\hline & Country & Value & Country & Value \\
\hline 3. & Slovenia & 0.9989 & Slovenia & 0.9944 \\
\hline 4. & Greece & 0.9934 & Italy & 0.9861 \\
\hline 5. & Belgium & 0.9887 & Greece & 0.9842 \\
\hline 6. & France & 0.9886 & Belgium & 0.9841 \\
\hline 7. & Italy & 0.9874 & Denmark & 0.9820 \\
\hline 8. & Denmark & 0.9873 & France & 0.9812 \\
\hline 9. & Norway & 0.9842 & Norway & 0.9759 \\
\hline 10. & Romania & 0.9792 & Romania & 0.9730 \\
\hline 11. & Germany & 0.9756 & Germany & 0.9641 \\
\hline 12. & Spain & 0.9736 & Lithuania & 0.9526 \\
\hline 13. & Portugal & 0.9723 & Spain & 0.9518 \\
\hline 14. & Lithuania & 0.9641 & Portugal & 0.9495 \\
\hline 15. & Poland & 0.9627 & Poland & 0.9494 \\
\hline 16. & Bulgaria & 0.9579 & Bulgaria & 0.9479 \\
\hline 17. & Latvia & 0.9425 & Latvia & 0.9171 \\
\hline 18. & Slovakia & 0.9325 & Austria & 0.9037 \\
\hline 19. & Austria & 0.9226 & Slovakia & 0.9020 \\
\hline 20. & Croatia & 0.9101 & Croatia & 0.8984 \\
\hline 21. & Sweden & 0.8750 & Sweden & 0.8562 \\
\hline 22. & Ireland & 0.7947 & Czechia & 0.7591 \\
\hline 23. & Czechia & 0.7847 & Ireland & 0.7589 \\
\hline 24. & UK & 0.7696 & UK & 0.7394 \\
\hline 25. & Hungary & 0.7629 & Hungary & 0.7295 \\
\hline \multirow[t]{2}{*}{26.} & Finland & 0.6551 & Finland & 0.6364 \\
\hline & $\mathrm{M}(4)$ & 0.9255 & $\mathrm{M}(7)$ & 0.9106 \\
\hline
\end{tabular}

$\mathrm{M}(\mathrm{x})$ is the mean value of acquired results for window width 4 or 7 .

Table A3. Window analysis results with different window width for the reference period 2005-2022.

\begin{tabular}{ccccccc}
\hline & \multicolumn{2}{c}{ Win(3) } & \multicolumn{2}{c}{ Win(6) } & \multicolumn{2}{c}{ Win(9) } \\
\hline & Country & Efficiency & Country & Efficiency & Country & Efficiency \\
\hline 1. & Estonia & 1.0000 & Estonia & 0.9999 & Estonia & 0.9998 \\
\hline 2. & Netherlands & 0.9999 & Netherlands & 0.9996 & Netherlands & 0.9993 \\
\hline 3. & Slovenia & 0.9994 & Slovenia & 0.9968 & Slovenia & 0.9948 \\
\hline 4. & Greece & 0.9969 & Greece & 0.9894 & Greece & 0.9851 \\
\hline 5. & France & 0.9925 & France & 0.9866 & Italy & 0.9806 \\
\hline 6. & Italy & 0.9914 & Belgium & 0.9846 & Belgium & 0.9799 \\
\hline 7. & Norway & 0.9912 & Denmark & 0.9830 & France & 0.9762 \\
\hline 8. & Belgium & 0.9909 & Italy & 0.9821 & Denmark & 0.9760 \\
\hline 9. & Denmark & 0.9902 & Norway & 0.9800 & Romania & 0.9737 \\
\hline 10. & Romania & 0.9857 & Romania & 0.9778 & Norway & 0.9711 \\
\hline
\end{tabular}


Table A3. Cont.

\begin{tabular}{|c|c|c|c|c|c|c|}
\hline & \multicolumn{2}{|c|}{$\operatorname{Win}(3)$} & \multicolumn{2}{|c|}{ Win(6) } & \multicolumn{2}{|c|}{ Win(9) } \\
\hline & Country & Efficiency & Country & Efficiency & Country & Efficiency \\
\hline 11. & Spain & 0.9841 & Portugal & 0.9645 & Spain & 0.9547 \\
\hline 12. & Portugal & 0.9819 & Spain & 0.9635 & Lithuania & 0.9525 \\
\hline 13. & Lithuania & 0.9793 & Lithuania & 0.9635 & Portugal & 0.9486 \\
\hline 14. & Poland & 0.9746 & Poland & 0.9562 & Bulgaria & 0.9441 \\
\hline 15. & Bulgaria & 0.9704 & Bulgaria & 0.9556 & Poland & 0.9427 \\
\hline 16. & Latvia & 0.9662 & Germany & 0.9519 & Germany & 0.9402 \\
\hline 17. & Germany & 0.9655 & Latvia & 0.9397 & Latvia & 0.9168 \\
\hline 18. & Slovakia & 0.9488 & Slovakia & 0.9216 & Austria & 0.8973 \\
\hline 19. & Austria & 0.9306 & Austria & 0.9128 & Slovakia & 0.8903 \\
\hline 20. & Sweden & 0.8918 & Croatia & 0.8696 & Croatia & 0.8548 \\
\hline 21. & Croatia & 0.8884 & Sweden & 0.8683 & Sweden & 0.8521 \\
\hline 22. & Ireland & 0.7830 & Czechia & 0.7552 & Czechia & 0.7297 \\
\hline 23. & Czechia & 0.7799 & Ireland & 0.7445 & Ireland & 0.7280 \\
\hline 24. & Hungary & 0.7714 & Hungary & 0.7341 & Hungary & 0.7076 \\
\hline 25. & UK & 0.7552 & UK & 0.7274 & UK & 0.7017 \\
\hline \multirow[t]{2}{*}{26.} & Finland & 0.6703 & Finland & 0.6464 & Finland & 0.6320 \\
\hline & $\mathrm{M}(3)$ & 0.9300 & $\mathrm{M}(6)$ & 0,9136 & $\mathrm{M}(9)$ & 0.9011 \\
\hline
\end{tabular}

$\mathrm{M}(\mathrm{x})$ is the mean value of acquired results for window width 3,6 or 9.

\section{References}

1. Bellmann, C.; Hepburn, J. The Decline of Commodity Prices and Global Agricultural Trade Negotiations: A Game Changer? Rev. Int. Polit. Dév. 2017. [CrossRef]

2. European Commision. Future of the Common Agricultural Policy. Available online: https://ec.europa.eu/info/food-farmingfisheries/key-policies/common-agricultural-policy/future-cap_en (accessed on 7 December 2020).

3. Petit, M. An Inside View of the CAP Reform Process: Explaining the MacSharry, Agenda 2000, and Fischler Reforms. EuroChoices 2011, 10, 62. [CrossRef]

4. Ouenniche, J.; Carrales, S. Assessing efficiency profiles of UK commercial banks: A DEA analysis with regression-based feedback. Ann. Oper. Res. 2018, 266, 551-587. [CrossRef]

5. Kohl, S.; Schoenfelder, J.; Fügener, A.; Brunner, J.O. The use of Data Envelopment Analysis (DEA) in healthcare with a focus on hospitals. Health Care Manag. Sci. 2019, 22, 245-286. [CrossRef]

6. Niavis, S.; Tsiotas, D. Assessing the tourism performance of the Mediterranean coastal destinations: A combined efficiency and effectiveness approach. J. Destin. Mark. Manag. 2019, 14, 100379. [CrossRef]

7. Martí, L.; Martín, J.C.; Puertas, R. A DEA-logistics performance index. J. Appl. Econ. 2017, 20, 169-192. [CrossRef]

8. Singh, P.; Singh, G.; Sodhi, G.P.S. Applying DEA optimization approach for energy auditing in wheat cultivation under rice-wheat and cotton-wheat cropping systems in north-western India. Energy 2019, 181, 18-28. [CrossRef]

9. Theodoridis, A.; Ragkos, A.; Roustemis, D.; Galanopoulos, K.; Abas, Z.; Sinapis, E. Assessing technical efficiency of Chios sheep farms with data envelopment analysis. Small Rumin. Res. 2012, 107, 85-91. [CrossRef]

10. Le, T.L.; Lee, P.P.; Peng, K.C.; Chung, R.H. Evaluation of total factor productivity and environmental efficiency of agriculture in nine east Asian countries. Agric. Econ. 2019, 65, 249-258. [CrossRef]

11. Zhou, X.; Chen, H.; Wang, H.; Lev, B.; Quan, L. Natural and managerial disposability based DEA model for China's regional environmental efficiency assessment. Energies 2019, 12, 3436. [CrossRef]

12. Atici, K.B.; Podinovski, V.V. Using data envelopment analysis for the assessment of technical efficiency of units with different specialisations: An application to agriculture. Omega 2015, 54, 72-83. [CrossRef]

13. Toma, E.; Dobre, C.; Dona, I.; Cofas, E. DEA Applicability in Assessment of Agriculture Efficiency on Areas with Similar Geographically Patterns. Agric. Agric. Sci. Procedia 2015, 6, 704-711. [CrossRef]

14. Searchinger, T.D.; Wirsenius, S.; Beringer, T.; Dumas, P. Assessing the efficiency of changes in land use for mitigating climate change. Nature 2018, 564, 249-253. [CrossRef] [PubMed]

15. Bournaris, T.; Vlontzos, G.; Moulogianni, C. Efficiency of Vegetables Produced in Glasshouses: The Impact of Data Envelopment Analysis (DEA) in Land Management Decision Making. Land 2019, 8, 17. [CrossRef] 
16. Food and Agriculture Organization of the United Nations (FAO). Energy, Agriculture and Climate Change: Towards Energy-Smart Agriculture. Available online: http:/ / www.fao.org/3/a-i6382e.pdf (accessed on 22 November 2020).

17. Pellegrini, P.; Fernández, R.J. Crop intensification, land use, and on-farm energy-use efficiency during the worldwide spread of the green revolution. Proc. Natl. Acad. Sci. USA 2018, 115, 2335-2340. [CrossRef]

18. Moradi, M.; Nematollahi, M.A.; Khaneghah, A.M.; Pishgar-Komleh, S.H.; Rajabi, M.R. Comparison of energy consumption of wheat production in conservation and conventional agriculture using DEA. Environ. Sci. Pollut. Res. 2018, 25, 35200-35209. [CrossRef]

19. Smith, L.G.; Williams, A.G.; Pearce, B.D. The energy efficiency of organic agriculture: A review. Renew. Agric. Food Syst. 2015, 30, 280-301. [CrossRef]

20. Guth, M.; Smędzik-Ambroży, K. Economic resources versus the efficiency of different types of agricultural production in regions of the European union. Econ. Res. Ekon. Istraz. 2020, 33, 1036-1051. [CrossRef]

21. Gadanakis, Y.; Bennett, R.; Park, J.; Areal, F.J. Evaluating the Sustainable Intensification of arable farms. J. Environ. Manag. 2015, 150, 288-298. [CrossRef]

22. Ghali, M.; Latruffe, L.; Daniel, K. Efficient use of energy resources on French farms: An analysis through technical efficiency. Energies 2016, 9, 601. [CrossRef]

23. Lin, X.; Zhu, X.; Han, Y.; Geng, Z.; Liu, L. Economy and carbon dioxide emissions effects of energy structures in the world: Evidence based on SBM-DEA model. Sci. Total Environ. 2020, 729, 138947. [CrossRef] [PubMed]

24. Apergis, N.; Aye, G.C.; Barros, C.P.; Gupta, R.; Wanke, P. Energy efficiency of selected OECD countries: A slacks based model with undesirable outputs. Energy Econ. 2015, 51, 45-53. [CrossRef]

25. Pishgar-Komleh, S.H.; Čechura, L.; Kuzmenko, E. Modeling Undesirable Factor in Efficiency Assessment of Agricultural Sector within EU-27 Countries and Over a Time Period. In Proceedings of the 2nd International Conference on Management, Economics, and Finance, Rotterdam, The Netherlands, 15-17 November 2019. [CrossRef]

26. Victor, M.; Margarita, R.; Pedro, M. Economic-environmental efficiency of European agriculture-A generalized maximum entropy approach. Agric. Econ. 2018, 64, 423-435. [CrossRef]

27. Fei, R.; Lin, B. The integrated efficiency of inputs-outputs and energy- $\mathrm{CO}_{2}$ emissions performance of China's agricultural sector. Renew. Sustain. Energy Rev. 2017, 75, 668-676. [CrossRef]

28. Laso, J.; Hoehn, D.; Margallo, M.; García-Herrero, I.; Batlle-Bayer, L.; Bala, A.; Fullana-i-Palmer, P.; Vázquez-Rowe, I.; Irabien, A.; Aldaco, R. Assessing energy and environmental efficiency of the Spanish agri-food system using the LCA/DEA methodology. Energies 2018, 11, 3395. [CrossRef]

29. Gancone, A.; Pubule, J.; Rosa, M.; Blumberga, D. Evaluation of agriculture eco-efficiency in Latvia. Energy Procedia 2017, 128, 309-315. [CrossRef]

30. Rebolledo-Leiva, R.; Angulo-Meza, L.; Iriarte, A.; González-Araya, M.C. Joint carbon footprint assessment and data envelopment analysis for the reduction of greenhouse gas emissions in agriculture production. Sci. Total Environ. 2017, 593, 36-46. [CrossRef]

31. Mardani, A.; Streimikiene, D.; Balezentis, T.; Saman, M.Z.M.; Nor, K.M.; Khoshnava, S.M. Data envelopment analysis in energy and environmental economics: An overview of the state-of-The-Art and recent development trends. Energies 2018, 11, 2002. [CrossRef]

32. Sueyoshi, T.; Goto, M. DEA non-radial approach for resource allocation and energy usage to enhance corporate sustainability in Japanese manufacturing industries. Energies 2019, 12, 1785. [CrossRef]

33. Sueyoshi, T.; Goto, M. Comparison among three groups of solar thermal power stations by data envelopment analysis. Energies 2019, 12, 2454. [CrossRef]

34. Mo, F.; Wang, D. Environmental sustainability of road transport in OECD countries. Energies 2019, 12, 3525. [CrossRef]

35. Suzigan, L.H.; Peña, C.R.; Guarnieri, P. Eco-efficiency Assessment in Agriculture: A Literature Review Focused on Methods and Indicators. J. Agric. Sci. 2020, 12, 118. [CrossRef]

36. Pishgar-Komleh, S.H.; Zylowski, T.; Rozakis, S.; Kozyra, J. Efficiency under different methods for incorporating undesirable outputs in an LCA + DEA framework: A case study of winter wheat production in Poland. J. Environ. Manag. 2020, $260,110138$. [CrossRef]

37. Ullah, A.; Perret, S.R.; Gheewala, S.H.; Soni, P. Eco-efficiency of cotton-cropping systems in Pakistan: An integrated approach of life cycle assessment and data envelopment analysis. J. Clean. Prod. 2016, 134, 623-632. [CrossRef]

38. Ewertowska, A.; Pozo, C.; Gavaldà, J.; Jiménez, L.; Guillén-Gosálbez, G. Combined use of life cycle assessment, data envelopment analysis and Monte Carlo simulation for quantifying environmental efficiencies under uncertainty. J. Clean. Prod. 2017, 166, 771-783. [CrossRef]

39. Lorenzo-Toja, Y.; Vázquez-Rowe, I.; Marín-Navarro, D.; Crujeiras, R.M.; Moreira, M.T.; Feijoo, G. Dynamic environmental efficiency assessment for wastewater treatment plants. Int. J. Life Cycle Assess. 2018, 23, 357-367. [CrossRef]

40. Theodoridis, A.; Ragkos, A.; Koutouzidou, G. Revealing the profile of economically efficient mussel farms: A restricted data envelopment analysis application. Aquac. Int. 2020, 28, 675-689. [CrossRef]

41. Zhou, H.; Yang, Y.; Chen, Y.; Zhu, J. Data envelopment analysis application in sustainability: The origins, development and future directions. Eur. J. Oper. Res. 2018, 264, 1-16. [CrossRef]

42. Swinnen, J.; Knops, L. (Eds.) Land, Labor and Capital Markets in European Agriculture: Diversity under a Common Policy; Centre for European Policy Studies: Brussels, Belgium, 2013; ISBN 978-94-6138-351-8. 
43. Giannakis, E.; Bruggeman, A. Exploring the labour productivity of agricultural systems across European regions: A multilevel approach. Land Use Policy 2018, 77, 94-106. [CrossRef]

44. Marinoudi, V.; Sørensen, C.G.; Pearson, S.; Bochtis, D. Robotics and labour in agriculture. A context consideration. Biosyst. Eng. 2019, 184, 111-121. [CrossRef]

45. Rybaczewska-Błazejowska, M.; Gierulski, W. Eco-efficiency evaluation of agricultural production in the EU-28. Sustainability 2018, 10, 4544. [CrossRef]

46. Forleo, M.B.; Palmieri, N.; Suardi, A.; Coaloa, D.; Pari, L. The eco-efficiency of rapeseed and sunflower cultivation in Italy. Joining environmental and economic assessment. J. Clean. Prod. 2018, 172, 3138-3153. [CrossRef]

47. Ng, C.Y.; Chuah, K.B.; King, A.P. yuk An integrated approach for the benchmarking of production facilities' environmental performance: Data envelopment analysis and life cycle assessment. Int. J. Sustain. Eng. 2019, 12, 108-114. [CrossRef]

48. Arabshahi, H.; Fazlollahtabar, H. A DEA-based framework for innovation risk management in production systems: Case study of innovative activities in industries. Int. J. Environ. Sci. Technol. 2017, 14, 2193-2204. [CrossRef]

49. Vlontzos, G.; Pardalos, P.M. Assess and prognosticate green house gas emissions from agricultural production of EU countries, by implementing, DEA Window analysis and artificial neural networks. Renew. Sustain. Energy Rev. 2017, 76, 155-162. [CrossRef]

50. Shabanpour, H.; Yousefi, S.; Saen, R.F. Forecasting efficiency of green suppliers by dynamic data envelopment analysis and artificial neural networks. J. Clean. Prod. 2017, 142, 1098-1107. [CrossRef]

51. Sueyoshi, T.; Goto, M. Performance assessment of Japanese electric power industry: DEA measurement with future impreciseness. Energies 2020, 13, 490. [CrossRef]

52. Zarbi, S.; Shin, S.-H.; Shin, Y.-J. An Analysis by Window DEA on the Influence of International Sanction to the Efficiency of Iranian Container Ports. Asian J. Shipp. Logist. 2019, 35, 163-171. [CrossRef]

53. Sánchez-Ortiz, J.; Garcia-Valderrama, T.; Rodríguez-Cornejo, V.; Cabrera-Monroy, F. DEA window analysis and Malmquist index to assess efficiency and productivity in the Spanish electricity sector. Int. J. Energy Sect. Manag. 2020. [CrossRef]

54. Sefeedpari, P.; Shokoohi, Z.; Pishgar-Komleh, S.H. Dynamic energy efficiency assessment of dairy farming system in Iran: Application of window data envelopment analysis. J. Clean. Prod. 2020, 275, 124178. [CrossRef]

55. Zhang, A.; Li, A.; Gao, Y. Social sustainability assessment across provinces in China: An analysis of combining intermediate approach with Data Envelopment Analysis (DEA) window analysis. Sustainability 2018, 10, 732. [CrossRef]

56. Farrell, M.J. The Measurement of Productive Efficiency. J. R. Stat. Soc. Ser. A 1957, 120, 253-290. [CrossRef]

57. Banker, A.R.D.; Charnes, A.; Cooper, W.W. Some Models for Estimating Technical and Scale Inefficiencies in Data Envelopment Analysis Some Models For Estimating Technical And Scale Inefficiencies In Data Envelopment Analysis. Manag. Sci. 1984, 30, 1078-1092. [CrossRef]

58. Zhu, J. Quantitative Models for Performance Evaluation and Benchmarking; International Series in Operations Research \& Management Science; Springer International Publishing: Cham, Switzerland, 2014; Volume 213, ISBN 978-3-319-06646-2.

59. You, S.; Yan, H. A new approach in modelling undesirable output in DEA model. J. Oper. Res. Soc. 2011, 62, 2146-2156. [CrossRef]

60. Scheel, H. Undesirable outputs in efficiency valuations. Eur. J. Oper. Res. 2001, 132, 400-410. [CrossRef]

61. Jahanshahloo, G.R.; Lotfi, F.H.; Shoja, N.; Tohidi, G.; Razavyan, S. Undesirable inputs and outputs in DEA models. Appl. Math. Comput. 2005, 169, 917-925. [CrossRef]

62. Charnes, A.; Clark, C.T.; Cooper, W.W.; Golany, B. A developmental study of data envelopment analysis in measuring the efficiency of maintenance units in the U.S. air forces. Ann. Oper. Res. 1984, 2, 95-112. [CrossRef]

63. Asmild, M.; Paradi, J.C.; Aggarwall, V.; Schaffnit, C. Combining DEA window analysis with the Malmquist index approach in a study of the Canadian banking industry. J. Product. Anal. 2004, 21, 67-89. [CrossRef]

64. Hao, C.; Xiaohong, W.; Baoesheng, Z. Evaluation of Scientific Research Efficiency of Universities in China Based on Window Analysis Model. Sci. Res. Manag. 2013, 7, 101-111.

65. Lin, S.; Sun, J.; Marinova, D.; Zhao, D. Evaluation of the green technology innovation efficiency of China's manufacturing industries: DEA window analysis with ideal window width. Technol. Anal. Strateg. Manag. 2018, 30, 1166-1181. [CrossRef]

66. EUROSTAT. Available online: https:/ / ec.europa.eu/eurostat/web/agriculture/data/database (accessed on 20 November 2020).

67. Minitab 17 Statistical Software, Product version 17.3.1; Computer Software; Minitab, Inc.: State College, PA, USA, 2010.

68. RStudio. Product Version 4.0.3; Computer Software; Boston, MA, USA. Available online: https:/ /www.rstudio.com/ (accessed on 22 December 2020).

69. Europearn Comission. Performance of the Agricultural Sector. Available online: https://ec.europa.eu/eurostat/statisticsexplained/index.php/Performance_of_the_agricultural_sector\#Value_of_agricultural_output (accessed on 22 December 2020).

70. Europearn Comission. EU Agricultural Outlook for the Agriculural Markets and Income 2017-2030. Available online: https://ec. europa.eu/info/sites/info/files/food-farming-fisheries/farming/documents/agricultural-outlook-2017-30_en.pdf (accessed on 19 January 2021).

71. European Commission. Agenda 2000-Volume I-Communication: For a Stronger and Wider Union. Available online: https: / / ec.europa.eu/commission/presscorner/detail/en/DOC_97_6 (accessed on 30 December 2020).

72. Rose, D.C.; Sutherland, W.J.; Barnes, A.P.; Borthwick, F.; Ffoulkes, C.; Hall, C.; Moorby, J.M.; Nicholas-Davies, P.; Twining, S.; Dicks, L.V. Integrated farm management for sustainable agriculture: Lessons for knowledge exchange and policy. Land Use Policy 2019, 81, 834-842. [CrossRef] 
73. Skjærseth, J.B. Linking EU climate and energy policies: Policy-making, implementation and reform. Int. Environ. Agreem. Polit. Law Econ. 2016, 16, 509-523. [CrossRef]

74. The World Bank. Water in Agriculture. Available online: https://www.worldbank.org/en/topic/water-in-agriculture (accessed on 19 December 2020).

75. EUROSTAT. Shedding Light on Energy in the EU: A Guided Tour of Energys Statistics. Available online: https://ec.europa.eu/ eurostat/cache/infographs/energy/bloc-2c.html (accessed on 21 January 2021).

76. Castillo, C.P.; e Silva, F.B.; Lavalle, C. An assessment of the regional potential for solar power generation in EU-28. Energy Policy 2016, 88, 86-99. [CrossRef]

77. European Commission. Energy Prices and Costs in Europe. Available online: https://eur-lex.europa.eu/legal-content/EN/ TXT/PDF/?uri=CELEX:52020DC0951\&from=EN (accessed on 2 February 2021). 